\title{
Insight From the Consideration of REM Dreams, Non-REM Dreams, and Daydreams
}

\author{
Mark Blagrove and Chris Edwards \\ Swansea University
}

Alex Reid

Swansea University and University of York

Paul Bennett, Michelle Carr, and Jean-Baptiste Eichenlaub Swansea University

\author{
Katie Evans \\ Swansea University
}

\author{
Elaine van Rijn \\ Swansea University and Duke-National University \\ of Singapore Medical School
}

\author{
Josie Malinowski \\ University of East London \\ Josie Malinowski
}

Shauna McGee

University of Zurich

\begin{abstract}
Throughout history, there have been reports and claims that consideration of dreams can produce personal realizations and insight. We assessed Exploration-Insight scores associated with discussing REM and non-REM dreams in connection with recent waking life experiences. Thirty-one participants were cued in the sleep laboratory for a daydream report and then awakened from REM and N2 sleep for dream reports. Participants subsequently discussed each of their dream and daydream reports for 30-40 min with two experimenters, following the structured Ullman (1996) dream group discussion procedure. Participants assessed the benefit of discussing the reports by completing the Gains from (Day)Dream Interpretation (G[D]DI) questionnaire. We found no difference in G(D)DI scores between discussing REM and N2 dream reports, and no difference between dream and daydream discussions in engagement and thoroughness of exploring the reports. However, discussing dream reports produced higher scores on the G(D)DI Exploration-Insight subscale compared with discussing daydream reports. Significant differences were evident in items reflecting the learning
\end{abstract}

\footnotetext{
This article was published Online First December 17, 2018.

Mark Blagrove and Chris Edwards, Department of Psychology, Swansea University Sleep Laboratory, Swansea University; Elaine van Rijn, Department of Psychology, Swansea University Sleep Laboratory, Swansea University, and Centre for Cognitive Neuroscience, DukeNational University of Singapore Medical School; Alex Reid, Department of Psychology, Swansea University Sleep Laboratory, Swansea University, and Department of Psychology, University of York; Josie Malinowski, Department of Psychology, University of East London; Paul Bennett, Department of Psychology, Swansea University; Michelle Carr and Jean-Baptiste Eichenlaub, Department of Psychology, Swansea University Sleep Laboratory, Swansea University; Shauna McGee, Institute of Psychol-
}

ogy, University of Zurich; Katie Evans, Department of Psychology, Swansea University; Perrine Ruby, Lyon Neuroscience Research Centre, Brain Dynamics and Cognition team, INSERM UMRS 1028, CNRS UMR 5292, Université Claude Bernard Lyon 1.

Study funded by Bial Foundation Award, 2014/83 Electrophysiological Correlates of the Incorporation of Recent Memory Sources Into REM and Non-REM Dreams and of Levels of Insight Following REM and Non-REM Dream Interpretation.

Correspondence concerning this article should be addressed to Mark Blagrove, Department of Psychology, Swansea University Sleep Laboratory, Swansea University, Singleton Park, Swansea SA2 8PP, United Kingdom. E-mail: m.t.blagrove@swansea.ac.uk 


\begin{abstract}
of what the report means in terms of waking life issues. Frontal theta prior to waking from N2 was significantly associated with Exploration-Insight score obtained after N2 dream discussion, but this relationship was not found for REM dreams. The findings of high ratings of Exploration-Insight after discussing dreams were evident even though participants did not select the dream, unlike what can occur for home recorded dreams, and even though discussion was brief. We suggest that insight might be produced by embodied and metaphorical thinking in dreams.
\end{abstract}

Keywords: insight, dreaming, daydreaming, mind-wandering, sleep

Supplemental materials: http://dx.doi.org/10.1037/cns0000167.supp

Throughout history, there have been reports that consideration of dreams can produce personal realizations and insight. For example, there are claims that the inspiration for inventing the sewing machine needle and for writing the books Dracula and Frankenstein, resulted from the recall of dreams (Barrett, 2017; Maquet \& Ruby, 2004). There is also a longstanding anecdotal and clinical literature and many cultural beliefs about dream content (a) providing a source of insight regarding personal problems and situations and (b) stimulating personal growth (e.g., Cartwright, Tipton, \& Wicklund, 1980; Freud, 1900/1953; Knox, Hill, Hess, \& Crook-Lyon, 2008).

Our study of dreams, personal realizations, and insights following dream discussion was inspired by Clara Hill, who uses one-to-one sessions with a therapist following Hill's (1996) exploration-insight-action model of dream interpretation to show that insight from working with a recent dream is greater than when working with a report of a recent waking life event or with a dream of another person (Hill, Diemer, Hess, Hilliger, \& Seeman, 1993). Because Hill's method is designed for psychotherapy, we used the Ullman dream group discussion method (Ullman, 1996) designed for lay use. The procedure, detailed below, allows for description of as much as can be remembered of the dream and of recent waking life events and concerns, as well as questions from the dream group to identify and clarify connections between dream content and recent waking life experiences. Although the method is usually used in a group of approximately eight members, a controlled environment for research was favored here by including just three members: the person reporting the dream and two researchers (Mark Blagrove and Chris Edwards) trained in the Ullman method.
Edwards, Ruby, Malinowski, Bennett, and Blagrove (2013) addressed the claims of insight following dream discussion by studying group sessions that followed the Ullman (1996) method. The researchers assessed gains from the sessions with the Gains From Dream Interpretation (GDI) questionnaire (Heaton, Hill, Petersen, Rochlen, \& Zack, 1998), and, in particular, its Exploration-Insight subscale, which assesses insights regarding one's life, as well as insights about memory sources for the dream. The GDI was developed from responses to open-ended questions about what clients gained from dream sessions with a therapist, and it has been used to investigate how session outcome is affected by variables such as type of dream, therapist-facilitated versus self-guided procedures, and client and therapist characteristics. Edwards et al. (2013) differentiated between "aha" experiences that occur when a person realizes what waking life event is the source of part of their dream content, and "aha" experiences that occur when considering dream content produces some realization about one's waking life, self, concerns, relationships, situations or actions. Both of these types of aha experience contribute to the Exploration-Insight subscale. In their study, the mean Exploration-Insight subscale score was very high (8.17 on a scale from 1 to 9) and comparable to outcomes on the same measure from therapist-led sessions using the Hill (1996) method. Accordingly, the Ullman method is effective for establishing connections between dream content and recent waking life experiences.

It is thus plausible that dreams might be able to bring to conscious awareness, either explicitly or after free associations, material that is important but currently not being considered in waking life. Of course, it is also possible that any empathic conversation could do the same, 
and Edwards et al. (2015) tested this possibility with a comparison event discussion condition in which participants reported a recent significant event from their waking life. This event was discussed and considered using the Ullman technique, which was also used for the dream reports. The researchers found high ratings on the Exploration-Insight subscale for dreams that were significantly higher than for the comparison event discussion condition.

The goals of the current study were for participants to explore their REM dream, N2 dream, and daydream reports thoroughly by discussion with two experimenters, to become experientially involved in the process of discussing the three types of reports, and for the participants to provide assessments of the process and outcomes of the discussions in the three conditions. Our aim was to test the hypothesis that greater Exploration-Insight scores would be obtained from dream discussions than from daydream discussions, and to test for a possible difference in Exploration-Insight scores between discussions of REM and N2 dreams.

\section{Sleep, (REM/NREM) Dreams, and Insight}

The hypothesis that higher ExplorationInsight scores would be obtained from dream discussions than from daydream discussions was inspired by two sets of proposals and findings. First, researchers have shown that sleep is involved in cognitive insight (Darsaud et al., 2011; Wagner, Gais, Haider, Verleger, \& Born, 2004) and in the functional reorganization of the brain that subserves memory consolidation (Groch, Wilhelm, Diekelmann, \& Born, 2013; Stickgold \& Walker, 2013; Wagner, Gais, \& Born, 2001) and emotional regulation (Walker \& Van der Helm, 2009). Furthermore, in REM sleep (as compared to wakefulness), decreased activity in the dorsolateral prefrontal cortex and temporoparietal junction, increased or maintained activity in the limbic system (notably amygdala, medial prefrontal/anterior cingulate, hippocampus, and parahippocampal cortex), and modification of functional connectivity between multiple brain regions (Maquet et al., 1996, 2005; Nofzinger, Mintun, Wiseman, Kupfer, \& Moore, 1997), may enable a different organization of cognition. This organization may favor the triggering of emotional over neu- tral memories, the processing of spontaneous over actively selected thoughts, and an associative rather than a mainly logical mode of thinking (e.g., Cai, Mednick, Harrison, Kanady, \& Mednick, 2009; Carr \& Nielsen, 2015b). Other work shows that slow-wave sleep is also important for memory consolidation (e.g., Diekelmann \& Born, 2010), including the integration of new memories into current memory and schemata, which forms the basis of cognitive abstraction and facilitates insight (Lewis \& Durrant, 2011).

Second, various authors have proposed that the functional reorganization and plasticity during REM and non-REM (NREM) sleep is reflected in dream content (Llewellyn, 2013; Perogamvros, Dang-Vu, Desseilles, \& Schwartz, 2013; Wamsley, 2014), which may explain some famous claims of insight inspired by a dream (Cai et al., 2009; Maquet \& Ruby, 2004). Landmann et al. (2015) held that REM sleep might foster associative thinking, creativity and emotional memory, and that dreaming represents the mentation correlate for the disintegration of existing schemas and the innovative recombination of memory traces. This associative characteristic of dreams leads to the claim (see also Freud, 1900/1953) that the process of free-association to the elements of a dream leads back to the precipitating sources of the dream (Baylor \& Cavallero, 2001) and that the waking life free-associative process is similar to the flexible and creative cognitive processes suggested to be occurring during REM sleep (Walker, Liston, Hobson, \& Stickgold, 2002). One possible explanation for these creative cognitive processes is that there is a relative deactivation of dorsolateral prefrontal areas during REM (see Ruby, 2011 for a review), and, with diminished executive control, suppressed or inhibited thoughts may become more accessible in sleep (Wegner, Wenzlaff, \& Kozak, 2004).

Although some of this work may lead to the prediction that REM dreams in particular would be characterized by an ability to elicit insight, it is important to note that the neurocognitive approach to dreaming of Foulkes and Domhoff (e.g., Domhoff, 2018; Foulkes, 1985) deemphasizes differences between REM and NREM dreams in terms of dream content and the brain basis of dream formation. Although differing in some respects (Domhoff, 2005), this approach accords with Solms' (1997) work 
dissociating the cerebral mechanisms controlling REM sleep and dreaming, and accords with dreams in general being found to reflect the waking life concerns (Domhoff, 2003; LaraCarrasco, Simard, Saint-Onge, LamoureuxTremblay, \& Nielsen, 2013), social relationships and cognition (Revonsuo, Tuominen, \& Valli, 2015), and personally significant or emotional waking life events of the dreamer (Malinowski \& Horton, 2014; Propper, Stickgold, Keeley, \& Christman, 2007; van Rijn et al., 2015). Insight would, according to this neurocognitive approach, be proposed to occur in response to both REM and NREM dreams, with dreams from REM and NREM sleep marked by a freeing of associations, and thus, according to Hartmann (1995), even exhibiting similarities to psychotherapy.

\section{Metaphors, Dreams, and Insight}

We define metaphor here as a nonliteral representation of waking life. Metaphors can occur because the dream changes the context or attributes of waking life experiences (Antrobus, 1977). According to Hartmann (2011), insight from dreams derives from the central metaphorical image of the dream, which pictures, or provides a picture context for the dominant emotions of the dreamer. He illustrated this with a paradigmatic dream, "I was overwhelmed by a tidal wave," which he said contextualizes the dominant emotion of fear, terror or helplessness. Lakoff (1993) has explored the presence of metaphors in dreams at a more cognitive level, using the framework from Lakoff and Johnson's (1980) Metaphors We Live By. The main tenet of the latter book, also summarized in Lakoff (2014), is that much of our waking life thinking is derived from metaphors. For example, Lakoff and Johnson (1980) detailed how the metaphor "love is a journey" can generate associated concepts such as "Look how far we've come," "We're at a crossroads," and "It's been a long bumpy road" (pp.44-45, italics in original). Various authors have similarly proposed that in dreams we experience metaphors (Antrobus, 1977; Malinowski \& Horton, 2015; Ullman, 1969), and even form new metaphors. Moreover, metaphors generated from actions in dream imagery are typically more novel than are metaphors generated from actions in waking fantasy imagery (Kuiken \& Smith, 1991). Met- aphors could also be the way dreams diminish the emotional intensity of waking life experience by including it in a different, larger, or more distant context (Levin \& Nielsen, 2007; Vallat, Chatard, Blagrove, \& Ruby, 2017).

Davidson and Lynch (2012) provided evidence for the figurative or metaphorical expression of waking life in dream content. The researchers showed a high impact film of the events of 9/11 and a nonemotional educational film to participants. They found more literal, closely associated, and distantly associated (i.e., nonliteral) references to $9 / 11$ in dream reports after the 9/11 video than after the education video, with the most significant difference between conditions being distantly associated references. These findings suggest that dream imagery is produced by a connectionist process that results in literal and associative or metaphoric content (Malinowski \& Horton, 2015; States, 1998).

\section{Mind Wandering/Daydreaming as Comparison Condition}

The basis for the current study was the proposal that personal insight can result from a person considering his or her dreams, a view that contrasts with Hobson's contention that "I never learned anything from a client's dreams that I did not already know" (Hobson \& Schredl, 2011, p. 6). The latter view leads to the caution that any discussion can potentially produce insight. Accordingly, as daydream content is influenced by current waking life concerns, we considered daydreaming to be a suitable comparison condition. In addition, as daydreams are similar to dreams in terms of content, structure, and brain basis (see next paragraph), and are endogenously produced, they may be more suitable for a comparison condition than are waking life event reports. We followed Noreika, Valli, Markkula, Seppälä, and Revonsuo's (2010) method for collecting daydreams, in which the participant lies on a bed in the sleep laboratory and after $10 \mathrm{~min}$ is cued for a report of what has been going through his or her mind, although we acknowledge that other methods of eliciting daydream reports may produce daydreams with different characteristics.

Domhoff $(2011,2018)$ hypothesized that dreaming and daydreaming may be similar phe- 
nomena with different intensities and that both are subserved by all or part of the default mode network (DMN). The DMN is a set of interconnected brain regions that are spontaneously active during relaxed wakefulness, particularly when the individual is not focused on external tasks, or is focused internally on tasks such as retrieving autobiographical memories, thinking about what might happen in the future, or thinking about the perspectives of others (Buckner, Andrews-Hanna, \& Schacter, 2008; Legrand \& Ruby, 2009). Some empirically based arguments support the involvement of the DMN in mind wandering and in dreaming (Eichenlaub, Bertrand, Morlet, \& Ruby, 2014; Mittner, Hawkins, Boekel, \& Forstmann, 2016). Fox, Nijeboer, Solomonova, Domhoff, and Christoff (2013) compared the content of mind wandering and dreaming and contended that dreaming is an "intensified" version of waking mind wandering, although dreams tend to be longer, more visual, more immersive and more hallucinatory (in that one more often believes that a dream is reality than one believes that a daydream is reality). They also proposed, as did Hartmann (1996), that dreams are marked by an increase in bizarreness and fantasy, and a decrease in executive functions and visual inputs (which allows weakly activated problem solutions to enter awareness; Kounios \& Beeman, 2009), along the continuum from waking thought to mind wandering to dreaming.

Although the mindwandering and daydreaming literatures use various terminologies (e.g., stimulus independent thought, task-unrelated thought, spontaneous cognition, mind wandering, daydreaming), we used the term daydreaming with participants during the discussion sessions and so follow that usage herein. However, during the night in the sleep laboratory, we did not use the term daydream; rather, we obtained experiential reports after we asked participants to let their mind wander.

\section{Electrophysiological Correlates of Insight}

Numerous studies have provided evidence for the role of REM frontal theta activity in the processing of emotional memories (e.g., Hutchison \& Rathore, 2015; Popa, Duvarci, Popescu, Léna, \& Paré, 2010; Prehn-Kristensen et al., 2013) and in the integration of novel memories into existing knowledge frameworks (e.g., Durrant, Cairney, McDermott, \& Lewis, 2015). For example, in Nishida, Pearsall, Buckner, and Walker (2009), within REM naps, emotional memory consolidation was associated with frontal electroencephalography (EEG) theta power $(4-7 \mathrm{~Hz})$. Greater REM frontal theta power also characterizes individuals who have experienced a trauma but who do not have posttraumatic stress disorder and who are thus assumed to have adaptive emotional regulation and memory consolidation, compared with traumatized individuals diagnosed with posttraumatic stress disorder (Cowdin, Kobayashi, \& Mellman, 2014). However, while compelling evidence supports the benefit of REM sleep on offline memory consolidation and a role for frontal theta during REM sleep in the processing of emotional memories, recent studies highlight that NREM sleep and its related theta activity could be involved in such processing as well (e.g., Cairney, Durrant, Power, \& Lewis, 2015; Lehmann, Schreiner, Seifritz, \& Rasch, 2016). Accordingly, dreams that are accompanied by higher levels of frontal theta might involve greater levels of emotional processing (Eichenlaub et al., 2018), and we therefore speculated that Exploration-Insight scores after discussion of the dream may be related to frontal theta power within the last three minutes of the (REM or N2) sleep that produced the dream.

\section{Aims and Hypotheses}

The aim of our study was to explore whether there are Exploration-Insight differences between Ullman technique discussions of REM dreams, N2 dreams, and daydreams. From the review, which suggests that dreams may be an intensified form of daydreaming and that dreams may be related to memory reorganization processes during sleep, we hypothesized that Exploration-Insight would be higher for the discussion of dreams than for the discussion of daydreams. Regarding the comparison of REM and N2 dreams, our review documents a strong link between REM sleep and emotional memory processing and differences in brain activation between sleep stages, with REM in general being the most active (Ioannides, Kostopoulos, Liu, \& Fenwick, 2009), with regional activity prone to elicit associative and emotional thinking. Nevertheless, the neurocognitive approach 
emphasizes similarities in form and content between REM and NREM dreams, and argues that there are brain activity similarities in REM and N2 sleep, particularly in the dorsal medial prefrontal cortex and the precuneus/ posterior cingulate cortex (Domhoff, 2018). Furthermore, Solms (1997) documented the importance of the ventral medial prefrontal cortex and the temporoparietal junction to both REM and NREM dreaming. Given the lack of clarity regarding whether to expect differences between REM and N2 dreams in Exploration-Insight, we did not advance a hypothesis regarding differences between discussing REM and N2 dreams.

We asked participants to provide a dichotomous decision regarding the occurrence of any realization during each discussion session and to provide a description of any such realizations. We used this approach to assess the suitability of the daydream control condition, as this suitability required that daydreams be meaningful and relatable to everyday life, and that discussion of daydreams stimulate deliberations about waking life, that are roughly comparable to the discussion of dreams in this regard. We captured the quality and levels of insightfulness of deliberations and realizations using participant ratings on the Exploration-Insight subscale.

The difference between dreams and daydreams on measures of hallucination was proposed as the basis for embodied metaphor in dreams. In moving from quiet wakefulness into sleep, where reports of mentation occur, there is typically a decrease in reflective thinking and an increase in motor imagery, indicating interactions with an imaginary, hallucinatory world (Fosse, Stickgold, \& Hobson, 2001; Speth \& Speth, 2016). We therefore used a rating of level of motor movement in the dream or daydream (Carr \& Nielsen, 2015a) as one of the measures of hallucination.

As there are differences between males and females in attitude toward dreams and toward dream interpretation (Schredl \& Piel, 2008), we aimed to recruit equal numbers of males and females and to evaluate sex differences in Exploration-Insight. Finally, we also investigated the relationship of Exploration-Insight to frontal theta during the sleep stage from which the dream was elicited.

\section{Method}

\section{Participants}

Thirty-three participants (17 males, 16 females; aged $18-30, M_{\text {age }}=20.61, S D=3.07$ ) took part in the experiment. One participant did not fall asleep in the sleep laboratory and one participant reported a daydream but did not report any dreams. These two participants were thus not included in the analyses, resulting in a final sample of 31 participants ( 15 females, 16 males; aged $18-30$ years, $M=20.42, S D=$ 3.16).

All participants were students at Swansea University, and all were native English speakers. Participants were self-reported frequent dream recallers (defined as recalling dreams 4-7 days per week) who also met the following criteria: sleeping a minimum of $7 \mathrm{hr}$ per night, with no reported disorders that could affect sleep; nonsmokers; not taking recreational drugs; and not consuming excessive alcohol (defined as intake greater than 6 units of alcohol per night, or greater than 21 units per week. One unit is defined as $10 \mathrm{~mL} / 8 \mathrm{~g}$ of alcohol; one unit is present in approximately $284 \mathrm{~mL} / 0.5$ imperial pints of 3.5\% alcohol-by-volume beer, or in 80 $\mathrm{mL}$ of $12 \%$ alcohol-by-volume wine). Ethical approval for the study was obtained from the Research Ethics Committee of the Swansea University Department of Psychology.

Participants gave written informed consent to take part after being provided with information regarding the procedures. They were paid $£ 150$ (approximately \$231 USD) for their participation. We reiterated throughout the study that participants could terminate their involvement, including halting discussions, at any point without explanation. No participant terminated his or her involvement at any stage, and all dreams and daydreams were discussed. After the study was completed information was provided for consulting clinically qualified well-being services in the event of distress or discomfort engendered by reporting or discussing the dreams or daydreams.

\section{Procedure and Materials}

Daily activity log prior to the night in the sleep laboratory. Participants were instructed to keep a daily $\log$ for 10 consecutive days, recording their waking life experiences each 
day. The daily log was taken from Fosse, Fosse, Hobson, and Stickgold (2003) and consisted of the following three categories: major daily activities (MDAs), personally significant events (PSEs), and major concerns (MCs). Participants reported up to five experiences per category on each daily log, reporting also any accompanying emotions. On the night of the 10th day of keeping the $\log$, participants slept in the sleep laboratory to provide dream and daydream reports.

Sleep laboratory night. Sleep was monitored using polysomnography. EEG, electrooculography, and electromyography were continuously recorded using a Trackit 18/8 system (Lifelines Ltd, Stockbridge, U.K., sampling rate: $200 \mathrm{~Hz}$, bandwidth: 0.16-70 Hz). EEG electrodes were placed according to the standard 10-20 system at C3, C4, F3, F4, M1, and M2. Electrooculography electrodes were applied above the right outer canthus and below the left outer canthus; electromyography electrodes were applied on the chin muscles. The common reference was placed at $\mathrm{CPz}$ and the ground electrode on the forehead.

For daydream report collection, participants were informed that before going to sleep the equipment would need to be checked. They were told that while the equipment was checked they would be given the opportunity to experience how the dream reports would be collected during the night. The following text was read out to the participants:

\footnotetext{
We need you to lie down while we check the connections and that the recordings are free of interference, and that the muscle recordings work. Please lie down, we need you to have your eyes closed, but it is very important that you stay awake. Just think of anything, let your mind wander, but please don't fall asleep! Once we have checked everything we will sound the buzzer and play you the messages that we will play during the night. We will ask you what was going through your mind before the buzzer went. Although you will have been awake, please answer in as much detail as you can.
}

After 10 min lying down with lights off, the buzzer was sounded, and participants received the following recorded audio message played from a digital recorder through an intercom: "What was going through your mind before the buzzer?" To prompt the participants, they were next asked with a recorded message: "Can you remember anything else?" If a report was less than 20 words, another attempt to collect a report was made following another $10 \mathrm{~min}$ of lying down in bed. The following prompts were also available to use where appropriate: "Please elaborate, if you can" and "Can you remember anything about thoughts, images, people, places, scenes, actions, feelings, or anything else?"

Participants were then given the opportunity to sleep and sleep stages were scored in real time according to the American Academy of Sleep and Medicine Manual for the Scoring of Sleep (Iber, Ancoli-Israel, Chesson, \& Quan, 2007). Sleep stages were subsequently confirmed offline. Participants were awoken during sleep with the aim of collecting one REM dream report and one N2 dream report for later discussions. Awakenings were not scheduled during the first two sleep cycles, so as not to disrupt slow-wave sleep. The order of the first awakening (N2 or REM sleep) was counterbalanced as follows between participants:

(1) N2 and then REM from the third sleep cycle: two REM periods (or $3 \mathrm{hr}$ of sleep) were counted, followed by an N2 awakening, and then a REM awakening from the next REM period;

or

(2) REM from the third sleep cycle and then N2 from the fourth sleep cycle: two REM periods (or $3 \mathrm{hr}$ of sleep) were counted, followed by a REM awakening, and then an N2 awakening after the third REM period and hence in the fourth sleep cycle of the night.

If $3 \mathrm{hr}$ of sleep were obtained but two REM periods had not occurred, an awakening was scheduled in the next REM or N2 period, counterbalanced across participants, with an N2 or REM awakening after that. For all the awakenings, if no dream was reported or if a dream report was less than 20 words, an awakening was then conducted the next time that sleep stage occurred, with any counterbalanced awakening delayed until after this second-attempt awakening.

Participants were woken by the buzzer sounding 10 min into their REM or N2 period. After awakening, the same recorded audio message as used for daydream report collection was played through the intercom, followed by any of the same prompts available for daydream reports where appropriate. After giving their dream report, or response that no dream could be recalled, the participant was invited to go back to sleep until the next awakening. As a 
result of the awakenings, 24 participants gave a daydream, REM dream, and N2 dream report, five gave a daydream and REM dream report, one gave a daydream and $\mathrm{N} 2$ dream report, and one gave a REM dream and N2 dream report. Voicefiles of dream and daydream reports were sent to an external transcriber blind to the REM/ $\mathrm{N} 2 /$ wake status of the participant when each report was cued.

Dream discussion. The transcriptions were discussed with the participant in a dream discussion group comprising the participant, and two experimenters (Mark Blagrove and Chris Edwards) who are trained in the Ullman technique. For 29 participants, the discussions occurred 2-3 days after being in the sleep laboratory, whereas for two participants, the discussions occurred 6 days after being in the sleep laboratory due to scheduling reasons. Before the reports were discussed, each participant was asked to give a preliminary description of his or her recent waking life, as this information would be common for each of the discussions. The REM dream, N2 dream, and daydream discussions were counterbalanced and timed to each last up to $40 \mathrm{~min}$, and both the researchers and the participant were not told the REM dream/N2 dream/daydream status of the reports. Each session was digitally voice recorded. The length of time of each session and the length of time spent on each stage of the Ullman method were calculated from the session recordings so as to check whether the conditions differed on these variables.

Ullman technique. The Ullman (1996) "dream appreciation" technique involves the following stages:

1A. Reading of the dream aloud by the dreamer.

1B. Clarification of the dream report by the group asking questions of the dreamer.

2A. Brief discussion of the dream by the group members other than the dreamer so as to imagine what feelings they would have experienced if the dream were their own.

2B. Briefly eliciting these individuals' projections about the dream in terms of their own lives so as to give their symbolic or metaphorical meaning to the dream images as if it were their own dream. An aim of this stage is to illustrate to the dreamer how connections may be made between waking life and dream reports.

3A. Response by the dreamer to Stage 2 . The dreamer is not obliged to respond to what was said during Stage 2 but can comment on whether statements made in Stage 2 were relevant or not relevant to $\mathrm{him} / \mathrm{her}$.

3B.1. Description by the dreamer of his or her waking life context for the dream, in terms of the dreamer's life experiences, with particular emphasis on recent experiences and concerns.

3B.2. Reading the dream back to the dreamer, in the second person, so that any additional information about the dream or the dreamer's waking life can be obtained.

3B.3. Orchestration, in which all members of the group suggest connections between information that the dreamer has given about his or her dream and information the dreamer has given about the dreamer's life.

For a full description of the process, see Ullman (1996). The same process was used to discuss daydream reports. For dreams and daydreams at Stage 1A the participant read aloud the transcript produced from the sleep laboratory awakenings/cues. Note that Ullman (1996) did allow for a fourth follow-up stage in which, at the next meeting of the group, the dreamer can share thoughts and insights about the dream that have occurred to him or her in the time between the two group sessions. This stage was omitted as it is less amenable to experimental control than are the first three stages.

Participant ratings of discussions. After each discussion participants completed the GDI questionnaire (Heaton, Hill, Petersen, et al., 1998), amended so as to refer to dreams and daydreams, with (day)dream substituted for dream throughout. This amended version is here termed the Gains From (Day)Dream Interpretation (G[D]DI) questionnaire. The GDI and G(D)DI questionnaires contain 14 items with a 9-point scale for responding to each item (1 = strongly disagree to $9=$ strongly agree). Both questionnaires have three subscales: Exploration-Insight Gains, Experiential Gains, and Action Gains. The Action Gains subscale has five 
items, which refer to being able to change bad dreams (and, for this study, change bad daydreams), or change waking life cognitions or actions, as a result of the session. The Experiential Gains subscale comprises two items: "During the session, I was able to re-experience the feelings I had in my (day)dream" and "I felt like I was actually reliving the (day)dream during the session." This subscale was used to test whether the experimenters had succeeded in treating the three conditions equally in these discussions.

All G(D)DI subscales have a range of 1 to 9 . From the data collected here the internal reliability of the scales was assessed using G(D)DI scores from the daydream condition and the mean of G(D)DI scores for the REM and N2 dream conditions: Exploration-Insight Gains, Cronbach's $\alpha=.74$ (daydream) and .80 (dream); Action Gains, Cronbach's $\alpha=.85$ (daydream) and .81 (dream); Experiential Gains, Cronbach's $\alpha=.81$ (daydream) and .90 (dream).

The main hypothesized difference between dream and daydream conditions was based on the G(D)DI's Exploration-Insight subscale, which has the following items: Item 1 - "I was able to explore my (day)dream thoroughly during the session," Item 2 - "I learned more about what this (day)dream meant for me personally during the session," Item 6 - "I learned more from the session about how past events influence my present behavior," Item 7 - "I learned more about issues in my waking life from working with the (day)dream," Item 8 - "I felt like I was very involved in working with the (day) dream during the session," Item 12 - "I learned things that I would not have thought of on my own," and Item 13 - "I was able to make some connections, that I had not previously considered, between images in my (day)dream and issues in my waking life." Although scores on Items 1 and 8 are included in the ExplorationInsight subscale score, we aimed for no difference between conditions on Items 1 and 8, so as to demonstrate, as with the Experiential subscale, that the experimenters had succeeded in treating the three conditions equally in the discussions.

After completing the G(D)DI, participants were asked to respond to the following questions: "Did you experience any realization, or realizations, about yourself, or other people, or your life during the session you have just had? If 'yes,' can you please describe the realization(s) and when and how the realization(s) happened?" Participants wrote a description of any realization(s). At the end of the study three independent judges then categorized the realization descriptions using the following key, without knowledge of the REM dream, N2 dream or daydream condition of the discussion that led to the realization: 0 - "does not give any evidence for a realization of any sort," 1 - "refers to a realization about the discussion process, or about what happened in the dream," 2 - "refers to a realization about the waking life source(s) of the dream, or about connections between waking life and the dream content," 3 - "states there was a realization about the dreamer's self, about other people who the dreamer knows, or about the life of the dreamer," 4 - "states there was a realization about the dreamer's self, about other people who the dreamer knows, or about the life of the dreamer, and indicates that this realization is new or is greater than before the session," 5 - "refers to a realization that action or change is needed in the dreamer's life," and 6 - "refers to a realization that action or change is needed in the dreamer's life, and indicates that this realization is new or is greater than before the session."

This categorization follows the distinction made by Edwards et al. (2013) between insight about the sources of dream content and insight about one's waking life as a result of considering the dream, and also Hill's distinction between Exploration-Insight and Action Gains. There was good reliability between the three judges (Cronbach's $\alpha=.80$ ). The overall category for each realization description was calculated conservatively as the minimum category score from any judge.

Correspondence identification task between dream reports and daily logs. The transcribed digital recordings from the sleep laboratory were used to produce an initial dream or daydream report, which was considered at the start of the Ullman technique. After the discussion session a canonical dream or daydream report was then produced based on the initial dream or daydream report plus any additional or amended content of the report from the whole discussion session. After the discussion sessions, the participant was asked to identify correspondences between the canonical (day) 
dream reports and each of the daily logs they kept over the 10 days before entering the sleep laboratory. Details of the procedure are presented in van Rijn et al. (2018), which used some of the $\log$ and (day) dream report data from the current study for other research purposes. The mean number of correspondences from across the 10 daily $\operatorname{logs}$ was then calculated for each of the three daily log categories separately.

Independent scoring of (day)dream reports. Two judges, blind to the REM dream/N2 dream/daydream status of the reports, assessed the dream and daydream reports for level of perceptual imagery and hallucination using the following ratings from the Dreamlike Fantasy Scale (Foulkes, Spear, \& Symonds, 1966): 2 - "conceptual content, everydayish," 3 - "conceptual content, bizarre or unusual topics," 4 - "perceptual content, nonhallucinatory, everydayish, undramatic," 5 - "perceptual content, nonhallucinatory, bizarre or unusual, dramatic," 6 - "perceptual content, hallucinatory, everydayish, undramatic," and 7 - "perceptual content, hallucinatory, bizarre or unusual, dramatic." The first two ratings on the Dreamlike Fantasy scale refer to instances where the dreamer does not produce a dream report. These were not presented to scorers as participants had produced a report. These ratings are 0 - "no content reported, feels mind was blank," and 1 - "no content reported, feels something was going through his or her mind, but forgets what." Judges then rated the (day)dream reports in response to the following questions (from Carr $\&$ Nielsen, 2015a) on 10-point scales, where $1=$ not at all, and $9=$ extremely: "How much of a visual component was there?" "How much of a hearing component was there?" and "How much of a movement component was there?"

Spectral analysis. Quantitative EEG analysis was performed using Biopac Acquisition software (Biopac Systems Inc., Goleta, CA) on the last 3 min of the frontal EEG record of sleep preceding each awakening, after any parts of the record suggestive of artifact were excluded. In REM sleep, only 20-s EEG epochs free of REMs (i.e., tonic REM sleep) were considered, so as to exclude any potential effect of eye movements in the results. Power spectra were computed by a fast Fourier transform applied to each 20-s epoch; a Hamming window with 50\% overlap was used. Finally, the spectral power density was averaged across epochs in the theta band $(4-7 \mathrm{~Hz})$ to test our hypothesis that frontal theta power would be associated with subsequent Exploration-Insight score. REM and N2 were analyzed separately. Nonhypothesized spectral power density in the sigma $(12-16 \mathrm{~Hz})$ and beta $(16-25 \mathrm{~Hz})$ bands were also assessed as control wave bands.

\section{Statistical Analysis}

SPSS Version 22 was used to perform the statistical analyses. Comparisons of the variable means for the REM dream, N2 dream, and daydream conditions were performed using paired-sample $t$ tests. ANOVA was not used prior to $t$ tests as many participants had data for only two of the three conditions. For comparisons of REM, N2 and daydreaming conditions the alpha criterion was first set at .05 , and a Bonferroni correction to alpha was then applied, such that $\alpha=.05 / 3=.0167$, and significance of findings are stated for uncorrected and corrected alpha separately. REM and N2 data were combined for some analyses, and mean dream data compared to daydream data. Two-tailed tests were used for all comparisons of dream and daydream report and discussion variables except for the comparison of dream and daydream conditions for Exploration-Insight, where a one-tailed $t$ test was used as the mean for the dream condition was hypothesized to be greater than for the daydream condition. Effect size for all paired-sample $t$ tests that achieved significance $(p<.05)$ was calculated as $d_{\mathrm{z}}=t / \mathrm{sqrt}(n)$ (Lakens, 2013). Following Cohen (1988, p. 40 and p. 46), thresholds for $d_{\mathrm{z}}$ are small effect $=$ .14 , medium effect $=.35$, and large effect $=$ .57. The correlations between frontal EEG power and Exploration-Insight score were tested using Spearman's rho correlation coefficient (two-tailed, $p<.05$ ).

\section{Results}

Number of awakenings/cues, number of reports, and report length variables for the REM, $\mathrm{N} 2$, and daydream conditions are presented in Table 1 . The length of each report in words was calculated using Antrobus' (1983) definition:

the count of all words in sentences or phrases in which the subject was describing something that had occurred just before waking. It excluded "ahs," 
Table 1

Number of Counterbalanced REM and N2 Awakenings and Daydream Cues, Total Number of REM and N2 Dream and Daydream Reports of More Than 20 Words, and Mean (Standard Deviation), Minimum, and Maximum Word Length of Dream and Daydream Reports Used in the Discussions

\begin{tabular}{lccc}
\hline \multicolumn{1}{c}{ Awakenings/reports variables } & REM & N2 & Daydream \\
\hline Total awakenings/cues, $n$ & 31 & 43 & 39 \\
Total reports $\geq 20$ words, $n$ & 30 & 26 & 30 \\
Report length in words, $M(S D)$ & $130.80(59.64)$ & $96.23(39.89)^{*}$ & $84.37(42.28)^{* *}$ \\
Minimum report length in words & 44 & 51 & 26 \\
Maximum report length in words & 353 & 245 & 232 \\
\hline${ }^{*}<.05 .^{* *} p<.001$ (comparison with REM dream condition). &
\end{tabular}

"uhms," repeated and corrected words, and all commentary on the experience, the report, or the current status of the subject. (p. 563)

Dream and daydream report length includes any amendments made during the discussion sessions.

In Table 1, statistical analyses are only conducted for the variable mean report length in words. REM dreams were significantly longer than N2 dreams, $t(24)=2.39, p=.025, d_{\mathrm{z}}=.48$ and daydreams, $t(28)=5.17, p<.001, d_{\mathrm{z}}=.96$. N2 dreams and daydreams did not differ significantly in length, $t(24)=1.35, p=.191$.

Table 2 shows the total discussion time and time spent on each of the stages of the Ullman method, for the REM dream, N2 dream, and daydream conditions. The mean duration of the preliminary description of background waking life context, which occurred once, before the discussions, was $2.15 \min (S D=1.34)$.

The REM and N2 sessions did not differ significantly in discussion duration, whereas
REM discussions and N2 discussions were significantly longer than daydream discussions, $t(28)=5.28, p<.001, d_{\mathrm{z}}=.98$ and $t(24)=$ $3.85, p=.001, d_{\mathrm{z}}=.77$, respectively, for uncorrected and Bonferroni corrected alpha. For the duration of stages of the discussions, there were no significant differences between REM and $\mathrm{N} 2$ discussions (all $|t \mathrm{~s}|<1.29$, all $p \mathrm{~s}>$ $0.21)$. REM discussions were significantly longer than daydreaming discussions on stage 1, $t(28)=2.89, p=.007, d_{\mathrm{z}}=.54$, Stage 3B.1, $t(28)=3.10, p=.004, d_{\mathrm{z}}=.58$, and Stage 3 B.3, $t(28)=2.64, p=.013, d_{\mathrm{z}}=.49$, for uncorrected and Bonferroni corrected alpha. N2 discussions were significantly longer than daydreaming discussions on Stage 1, $t(24)=2.86$, $p=.009, d_{\mathrm{z}}=.57$, Stage 3B.1, $t(24)=2.08$, $p=.048, d_{\mathrm{z}}=.42$ and Stage 3B.3, $t(24)=$ $2.34, p=.028, d_{\mathrm{z}}=.47$, for uncorrected alpha. For Bonferroni corrected alpha, only the Stage 1 duration comparison was significant. The duration of the discussion sessions was significantly

Table 2

Mean (Standard Deviation) of Total Discussion Time and of Time Spent on Each of the Stages of the Ullman Method, in Minutes, for the REM Dream, N2 Dream, and Daydream Conditions

\begin{tabular}{lccc}
\hline \multicolumn{1}{c}{ Discussion session and stages } & $\begin{array}{c}\text { REM dream } \\
(n=30)\end{array}$ & $\begin{array}{c}\text { N2 dream } \\
(n=26)\end{array}$ & $\begin{array}{c}\text { Daydream } \\
(n=30)\end{array}$ \\
\hline Whole session & $35.71(6.23)^{* * * *}$ & $34.38(4.61)^{* * * *}$ & $30.77(4.09)$ \\
1.(Day)dream recounting & $9.26(1.97)^{* *}$ & $9.07(2.25)^{* *}$ & $7.63(2.47)$ \\
2. Group discusses (day)dream & $4.86(1.17)$ & $4.85(.97)$ & $5.00(1.39)$ \\
3A. Dreamer responds & $1.11(.82)$ & $1.01(.83)$ & $1.07(2.14)$ \\
3B.1. Recent waking life explored & $13.15(2.84)^{* *}$ & $12.13(2.36)^{*}$ & $10.91(3.30)$ \\
3B.2. (Day)dream playback & $1.50(.67)$ & $1.52(.68)$ & $1.55(.92)$ \\
3B.3. Orchestration & $5.84(2.20)^{*}$ & $5.80(1.97)^{*}$ & $4.61(1.39)$ \\
\hline
\end{tabular}

${ }^{*} p<.05 . \quad{ }^{* *} p<.01 .{ }^{* * *} p \leq .001$ (comparison with daydream condition). 
related to the length of reports for REM dreams $(r=.563, p=.001)$, N2 dreams $(r=.465, p=$ $.017)$, and daydreams $(r=.537, p=.003)$.

After each discussion session, participants responded to the following question: "Did you experience any realization, or realizations, about yourself, or other people, or your life during the session you have just had? If 'yes,' please can you describe the realization(s) and when and how the realization(s) happened?" Figure 1 shows that participants reported a realization after the majority of discussion sessions. The results were very similar for the REM dream, N2 dream, and daydream conditions in frequency of occurrence of realization (McNemar test, binomial distribution, for all comparisons $p>.26$ ).

Figure 2 shows the results from the judge categorizations of the realization descriptions reported by the participants for the REM dream, $\mathrm{N} 2$ dream, and daydream conditions, on the 6-point scale from 0 (does not give any evidence for a realization of any sort) to 6 (refers to a realization that action or change is needed in the dreamer's life, and indicates that this realization is new or is greater than before the session). Results include participant "no realization" ratings in the 0 category. One realization description was judged as not providing evidence for a realization and was hence recategorized as zero. The results were very similar for the REM dream, N2 dream, and daydream con- ditions in frequency of each category of realization (Wilcoxon's test, for all comparisons, $z<$ 1.05 and $p>.29$ ). Realizations about the self (that is, scores of 3 or higher) occurred in approximately half the discussions of REM dreams, N2 dreams, and daydreams. The other half of discussions involved no personal realization, or a realization just about the memory sources of the dream or daydream.

To illustrate a realization and its relationship to the dream report and discussion, the following is an example of a participant's dream report, a summary of the discussion, and the participant's realization report. The participant had recently moved from the family home to start being a student at Swansea University. The dream report was as follows:

\begin{abstract}
I was at home and found my dog in a chair. My dog was scared because it was thunder and lightning, I held my dog's mouth to stop her barking. I was carrying my dog around trying to calm her down and then I found the half-eaten bacon sandwich in my room, fed that to my dog and then she wasn't shaking anymore. I walked downstairs. It was like a grand staircase with like marble stairs. There were two people in my [university residence] hallway, next to the front door, talking, but one of them was someone who lives in the flat opposite, who was smoking and then I didn't know who the other one was, he smiled at me.
\end{abstract}

In the discussion, the dream group researchers asked about grand staircases, marble staircases and marble, and elicited the following responses from the dreamer:

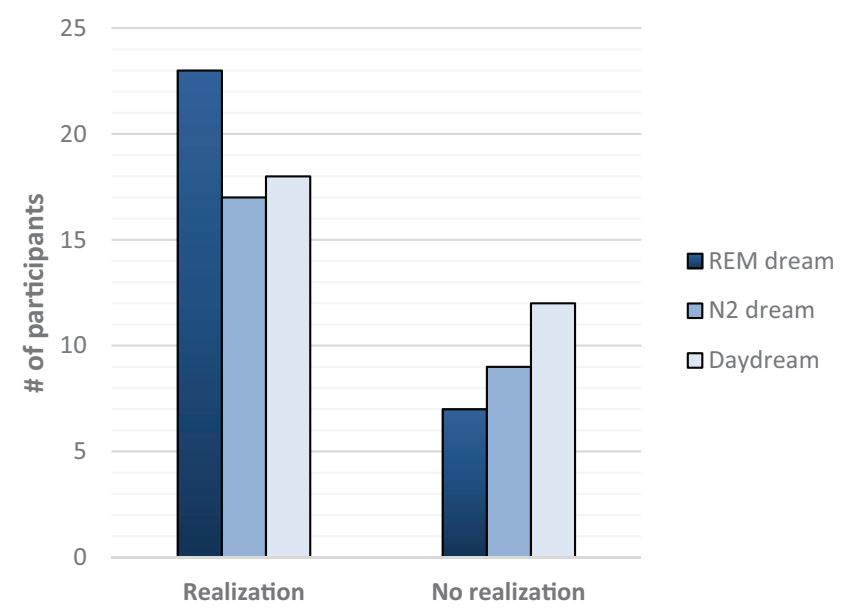

Figure 1. Participant responses to question on whether they had experienced any realization during each discussion session. See the online article for the color version of this figure. 


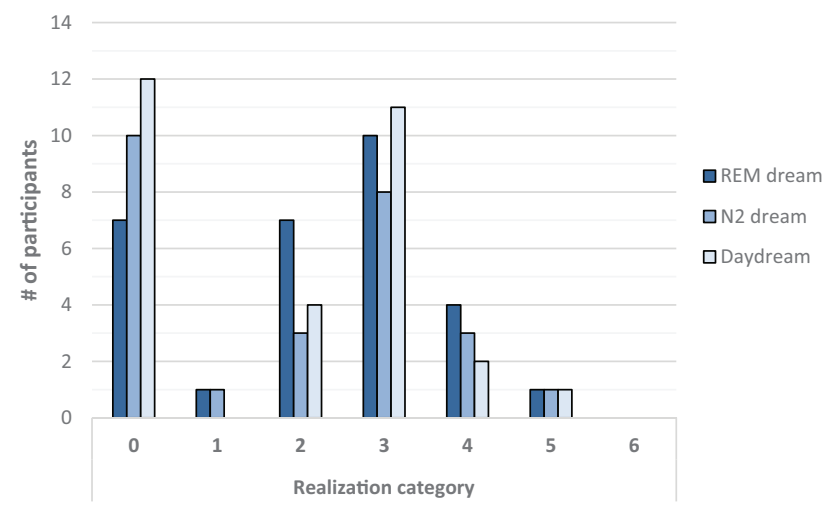

Figure 2. Judge categories of participant responses to the realization question. Participant "no realization" responses are included in the 0 category. Key to categories: $0=$ does not give any evidence for a realization of any sort; 1 = refers to a realization about the discussion process, or about what happened in the dream; 2 = refers to a realization about the waking life source(s) of the dream or about connections between waking life and the dream content; 3 = states there was a realization about the dreamer's self, about other people who the dreamer knows, or about the life of the dreamer; $4=$ states there was a realization about the dreamer's self, about other people who the dreamer knows, or about the life of the dreamer and indicates that this realization is new or is greater than before the session; $5=$ refers to a realization that action or change is needed in the dreamer's life; $6=$ refers to a realization that action or change is needed in the dreamer's life and indicates that this realization is new or is greater than before the session. See the online article for the color version of this figure.

I don't remember seeing any grand staircases during the week. . . . I think I had thought about the word "marble" like a few days before and then I was, I think I thought about it but hadn't seen any. ... I think it was like a marble-topped table, I think that comes from when we were on holiday [last family holiday before university] . . . there was a table [for the family meals] and it was, it was wooden on the inside but it had like kind of marble on the sides and on top.

After the session, the participant wrote a description of the realization: "Linking the dream to be about family life and the change of home to University has made me realize that the nostalgia of my family back home has had a greater influence on me than I'd first thought."

As shown here, the three conditions did not differ in number of realizations. The three conditions also did not differ on the Experiential subscale of the G(D)DI, which scores for the feeling of reliving the dream or daydream during the session and for reexperiencing in the session the feelings present in the dream or daydream. For the REM dream, N2 dream, and daydream conditions the means (and standard deviations) for the Experiential subscale were 7.00 (1.76), 7.21 (1.52), and 6.62 (1.79) respectively, and for the Action subscale were 5.29 (1.48), 5.39 (1.24), and 5.15 (1.60), respec- tively. There were no significant differences between conditions on these subscales (all $t \mathrm{~s}<$ 1.93). Although shorter than REM dream reports, daydreams thus seem to be a suitable comparison condition for dreams in the current study.

To address the main hypothesis, the mean scores on the Exploration-Insight subscale of the G(D)DI were calculated next. These scores were REM dream, $M=7.49(S D=1.01)$; N2 dream, $M=7.76$ (0.85); daydream, $M=7.13$ (0.99). Exploration-Insight was significantly higher for REM and N2 dreams than for daydreams for uncorrected alpha, $t(28)=1.83, p=$ $.035, d_{\mathrm{z}}=.34$, one-tail, and $t(24)=2.65, p=$ $.007, d_{\mathrm{z}}=.53$, one-tail, respectively, with Bonferroni-corrected alpha, only the comparison of N2 with daydreams was significant. REM dreams and N2 dreams did not differ significantly on Exploration-Insight, $t(24)=1.15$, $p=.262$. There were no significant differences between males and females on ExplorationInsight for N2 dreams, males $M=7.44$ (1.01), females $M=8.03(0.58) ; t(24)=1.87, p=$ .074 , REM dreams, males $M=7.36$ (1.14), females $M=7.65(0.84) ; t(28)=0.80, p=$ 
.429 , or daydreams, males $M=6.90$ (0.97), females $M=7.39(0.98) ; t(28)=1.36, p=$ .185. Partial correlations (with gender partialed out) were then computed for ExplorationInsight scores between N2 and REM discussions, $r(22)=.354, p=.089$, REM and daydreaming discussions, $r(26)=.481, p=.010$, and $\mathrm{N} 2$ and daydreaming discussions, $r(21)=$ $.486, p=.016$.

As REM and N2 dreams did not differ significantly on the Exploration-Insight subscale, nor, as reported above, on the Experiential or Action subscales, REM and N2 results were combined in the following G(D)DI analyses. Table 3 shows that, as hypothesized, Exploration-Insight was significantly higher for dreams than for daydreams, $t(29)=3.09, p=.002$, $d_{\mathrm{z}}=.56$, one-tail, with a medium to large effect size. Importantly, the dream and daydream discussions did not differ significantly on the participants' ratings of whether they explored the dream or daydream thoroughly during the session (Item 1), or on the participants' rating of having been very involved in working with the dream or daydream (Item 8). Nevertheless, on Exploration-Insight overall, and on subscale Item 2 ("I learned more about what this [day] dream meant for me personally during the session"), $t(29)=3.54, p<.001, d_{\mathrm{z}}=.65$, onetail, with a large effect size, Item 7 ("I learned more about issues in my waking life from work- ing with the [day]dream"), $t(29)=1.84, p=$ $.038, d_{\mathrm{z}}=.34$, one-tail, with a small to medium effect size, and Item 12 ("I learned things that I would not have thought of on my own"), $t(29)=3.21, p=.002, d_{\mathrm{z}}=.59$, one-tail, with a large effect size, there were significantly greater gains for dream than for daydream discussions. Item 13 ("I was able to make some connections, that I had not previously considered, between images in my [day]dream and issues in my waking life") did not differ significantly between dreams and daydreams but the difference approached significance, $t(29)=$ $1.70, p=.051, d_{\mathrm{z}}=.31$, one-tail.

The G(D)DI Exploration-Insight dream condition scores here are comparable with those from discussing dreams in Edwards et al. (2015) and in the work of Hill (as calculated by Edwards et al., 2013): $M=7.60(S D=0.88), M=$ $7.82(S D=0.84)$, and $M=7.40(S D=1.15)$, respectively. Scores are also comparable between the comparison daydream condition and the comparison condition (discussion of a recent significant event) in Edwards et al. (2015): $M=7.13(S D=0.99)$ and $M=7.21(S D=$ 1.13), respectively.

Correlations were computed between the Exploration-Insight scores and the judge ratings of what participants had written in their account of any realization during the sessions. For REM discussions, Spearman's $\rho=.40, p=.030 ; \mathrm{N} 2$

Table 3

Mean (Standard Deviation) of Gains From (Day)Dream Interpretation Questionnaire Exploration-Insight Subscale Scores for Dream and Daydream Conditions, and of Scores for the Seven Items of the Exploration-Insight Subscale $(N=30$, and $p$ Values for One-Tail t Test Comparing Dream and Daydream Conditions)

\begin{tabular}{|c|c|c|c|c|c|}
\hline \multirow[b]{2}{*}{ Exploration-Insight subscale and items } & \multicolumn{2}{|c|}{ Dream } & \multicolumn{2}{|c|}{ Daydream } & \multirow[b]{2}{*}{$p$} \\
\hline & $M$ & $S D$ & $M$ & $S D$ & \\
\hline Exploration-Insight subscale & 7.60 & .88 & 7.13 & .99 & .002 \\
\hline 1. I was able to explore my (day)dream thoroughly during the session & 8.35 & .97 & 8.07 & 1.20 & .117 \\
\hline $\begin{array}{l}\text { 2. I learned more about what this (day)dream meant for me personally during } \\
\text { the session }\end{array}$ & 8.00 & .86 & 7.07 & 1.48 & $<.001$ \\
\hline $\begin{array}{l}\text { 6. I learned more from the session about how past events influence my present } \\
\text { behaviour }\end{array}$ & 6.57 & 1.79 & 6.57 & 1.70 & .500 \\
\hline $\begin{array}{l}\text { 7. I learned more about issues in my waking life from working with the } \\
\text { (day)dream }\end{array}$ & 6.95 & 1.74 & 6.40 & 1.85 & .038 \\
\hline $\begin{array}{l}\text { 8. I felt like I was very involved in working with this (day)dream during the } \\
\text { session }\end{array}$ & 7.97 & 1.28 & 7.80 & 1.21 & .241 \\
\hline 12. I learned things that I would not have thought of on my own & 7.53 & 1.22 & 6.63 & 2.13 & .002 \\
\hline $\begin{array}{l}\text { 13. I was able to make some connections, that I had not previously considered, } \\
\text { between images in my (day)dream and issues in my waking life }\end{array}$ & 7.85 & .89 & 7.37 & 1.33 & .051 \\
\hline
\end{tabular}


discussions, $\rho=.24, p=.244$; daydream discussions, $\rho=.60, p=.001$. Overall these correlations evidence the validity of the participants' Exploration-Insight scores.

To address why the dream and daydream conditions differed significantly on Exploration-Insight, data on incorporation of recent waking life experiences into dreams and daydreams were examined. These incorporations are the correspondences between daily logs and (day)dream reports identified by participants. The means for the number of incorporations from the 10 days of diary reports that participants kept before coming to the sleep laboratory, on a per daily log basis, were computed for REM dreams, N2 dreams, and daydreams for each of MDAs, PSEs, and MCs. All differences between conditions on the number of incorporations of MDAs, PSEs, and MCs were nonsignificant (all $t \mathrm{~s}<1.26$, all $p \mathrm{~s}>.21$; data presented in Supplemental Material 1). However, for the log completed on the day of coming to the sleep laboratory, daydreams had significantly more incorporations of MCs than did REM dreams with uncorrected alpha (REM dreams, $M=0.20(S D=0.48)$; daydreams, $M=0.48(0.69)), t(28)=2.51, p=.018, d_{\mathrm{z}}=$ 0.47 ; however, this difference was not significant with Bonferroni corrected alpha. No significant differences were found between the number of incorporations of MCs from the day of coming to the sleep laboratory when comparing daydreams with $\mathrm{N} 2$ dreams, $t(23)=$ $0.62, p=.539$ or when comparing REM dreams with N2 dreams, $t(24)=1.69, p=.103$. There were also no significant differences between conditions for the incorporation into REM or N2 dreams or daydreams of MDAs or PSEs from the day of coming to the sleep laboratory (all $t \mathrm{~s}<1.28$, all $p \mathrm{~s}>.21$; data presented in Supplemental Material 1).
To address further why the daydream and dream conditions differed significantly on Exploration-Insight, data on the judge scores of dream characteristics were considered next. This follows from the proposal that embodied metaphors in dreams are predicated on dreams being hallucinatory rather than solely perceptual or cognitive. Table 4 reports judge scored Dreamlike Fantasy, and Visual, Hearing, and Movement scores for the REM dream, N2 dream, and daydream reports.

Dreamlike Fantasy was significantly higher for $\mathrm{N} 2$ dreams, $t(24)=8.89, p<.001, d_{\mathrm{z}}=$ 1.78 and REM dreams, $t(28)=8.66, p<.001$, $d_{\mathrm{z}}=1.61$, than for daydreams, but did not differ between REM and N2 dreams, $t(24)=0.81$, $p=.425$. Visual score was significantly higher for N2 dreams, $t(24)=3.57, p=.002, d_{\mathrm{z}}=.71$ and REM dreams, $t(28)=5.89, p<.001, d_{\mathrm{z}}=$ 1.09 than for daydreams, but did not differ between REM and N2 dreams, $t(24)=0.78$, $p=.442$. Movement score was significantly higher for N2 dreams, $t(24)=2.66, p=.014$, $d_{\mathrm{z}}=.53$ and REM dreams, $t(28)=3.51, p=$ $.002, d_{\mathrm{z}}=.65$ than for daydreams, but did not differ between REM and N2 dreams, $t(24)=$ $1.30, p=.205$. Where comparisons of dream characteristics here were significant, for uncorrected alpha, they were also significant for Bonferroni corrected alpha, except for the Movement score comparison between N2 dreams and daydreams. There were no significant differences between the three conditions on hearing score (all $t \mathrm{~s}<1.69$, all $p \mathrm{~s}>.10$ ).

However, there were also differences between dream and daydream conditions on report length (words $M=118.55$ [ $S D=42.81$ ], and $M=84.37[S D=42.28]$, for dreams and daydreams, respectively), and discussion duration (minutes $M=35.82[S D=4.76]$, and $M=$ $30.77[S D=4.09]$, for dreams and daydreams,

Table 4

Mean (Standard Deviation) Judge Scores of Dreamlike Fantasy, Visual, Hearing, and Movement for REM Dream, N2 Dream, and Daydream Reports

\begin{tabular}{llll}
\hline Report content variables & $\begin{array}{c}\text { REM dreams } \\
(n=30)\end{array}$ & $\begin{array}{c}\text { N2 dreams } \\
(n=26)\end{array}$ & $\begin{array}{c}\text { Daydreams } \\
(n=30)\end{array}$ \\
\hline Dream Fantasy Scale & $5.87(.76)^{* * *}$ & $6.02(.79)^{* * *}$ & $2.83(1.62)$ \\
Visual & $5.48(1.67)^{* * *}$ & $4.75(1.98)^{* *}$ & $2.97(1.84)$ \\
Hearing & $1.53(.90)$ & $1.87(1.22)$ & $1.80(1.44)$ \\
Movement & $2.83(1.51)^{* *}$ & $2.33(1.26)^{*}$ & $1.70(.79)$ \\
\hline
\end{tabular}

${ }^{*} p<.05 .{ }^{* *} p<.01 .{ }^{* * * *} p<.001$ (comparison with daydream condition). 
respectively), and so it was necessary to investigate controlling for these in the analysis of the difference in Exploration-Insight between dreams and daydreams. The significant difference between dream and daydream conditions on Exploration-Insight became nonsignificant when length in words of dream and daydream reports and duration of the dream and daydream discussions were used as covariates, $F(1,27)=$ $1.01, p=.324$, and $F(1,27)=0.12, p=.736$, respectively. The difference between conditions also became nonsignificant when Dreamlike Fantasy rating $(M=5.97[S D=0.59]$, and $M=2.83[S D=1.62]$, for dreams and daydreams, respectively) was used as a covariate, $F(1,27)=0.07, p=.801$. Although number of incorporations of MCs from the day of going to the sleep laboratory did not differ significantly between dreams (REM and N2 combined) and daydreams $(M=0.26[S D=0.47]$ and $M=$ $0.48[S D=0.69]$ for dreams and daydreams, respectively), $t(28)=1.94, p=.062$, as this difference did approach significance this variable was also used as a covariate, but was found not to account for the difference in ExplorationInsight, which remained significant, $F(1,26)=$ $6.06, p=.011$.

Given these results it is possible that the original significant difference in ExplorationInsight between dreams and daydreams is due to one of the confounding variables (i.e., report length, discussion duration, Dreamlike Fantasy rating). To investigate these possibilities multiple regressions were conducted for the REM dream, N2 dream, and daydream conditions separately, with Exploration-Insight as the dependent variable, and the following variables as predictors: number of words in report, length of discussion session, Dreamlike Fantasy rating, number of incorporations of PSEs from the previous 10 days, and number of incorporations of MCs from the previous 10 days. For REM dreams and N2 dreams analyzed separately, none of these variables was predictive of Exploration-Insight (REM dreams: model adjusted $R^{2}=-.133$, all $\mid$ standardized $\beta \mid<0.23$, all $p$ s $>.39$; N2 dreams: model adjusted $R^{2}=$ -.089 , all |standardized $\beta \mid<0.34$, all $p \mathrm{~s}>$ $.22)$. For daydreaming, none of the variables was predictive of Exploration-Insight except for Dreamlike Fantasy (standardized $\beta=$ $-.460, p=.024)$ and number of incorporations of PSEs (standardized $\beta=.489, p=.033$ ); all other predictors had Istandardized $\beta \mid<.37$, all ps $>.13$, model adjusted $R^{2}=.222$. Full details of the regression statistics are reported in Supplemental Material 2. Length of discussion and length of dream/daydream report were thus not predictive of Exploration-Insight for any condition; Dreamlike Fantasy was not predictive of Exploration-Insight for the REM or N2 conditions, but was a negative predictor of Exploration-Insight for daydreams.

Finally, we explored the neural underpinning of Exploration-Insight, by examining the correlation between frontal EEG theta power in the 3 min before the dream reports were given in the sleep laboratory and the scores on the Exploration-Insight subscale. This analysis showed a significant and positive correlation for the N2 condition at F4 (Spearman's $\rho=.51, p=.014$, $n=23$ ) but not F3 (Spearman's $\rho=.41, p=$ $.057, n=22$ ). Plots of these two correlations, EEG power data, and reasons for excluding some participants from EEG power analyses are presented in Supplemental Material 3. There was no significant theta correlation for REM sleep (F3: $\rho=.22, p=.307, n=24 ; \mathrm{F} 4: \rho=$ $.15, p=.462, n=25)$. There were also no significant correlations of Exploration-Insight subscale scores with F3 or F4 EEG sigma or beta power for REM (all $|\rho|<.15$, all $p \mathrm{~s}>.50$ ) or N2 (all $|\rho|<0.21$, all $p$ s $>.34)$.

\section{Discussion}

We successfully obtained in the sleep laboratory REM dream, N2 dream, and daydream reports that were subsequently discussed in accordance with the Ullman (1996) technique. Realizations about the self were reported in approximately half of the REM dream, N2 dream, and daydream discussions. The high level of realizations reported from daydream discussions confirms the appropriateness of the latter as a comparison condition. The realizations in the three conditions often referred to what might be ignored, overlooked, or not yet noticed in waking life. The dreamer often was aware of the issue already, but there may have been some blind-spot of memory or perception, as Erdelyi (2006) described in his work on suppressed and repressed thoughts. Participant ratings of the quality of the discussion sessions for eliciting realizations and insight were obtained on the G(D)DI Exploration-Insight sub- 
scale. REM and N2 conditions did not differ on G(D)DI scores, in line with one-generator models of dreaming (Domhoff, 2018; Nielsen, 2000; Solms, 2000), and participants' G(D)DI scores were thus combined. In confirmation of our main hypothesis, participants provided significantly higher ratings for their Exploration-Insight gains in the dream discussions compared with the daydream discussions. Regarding individual items, participants rated dream discussions significantly higher than daydream discussions on the following: "I learned things that I would not have thought of on my own," "I learned more about what this (day)dream meant for me personally during the session," and "I learned more about issues in my waking life from working with the (day)dream."

Using the G(D)DI, dream discussions were thus rated higher than daydream discussions on learning what the (day)dream report means for the dreamer in terms of waking life issues. We obtained these results even though participants did not select the dreams, as they were the dreams collected in the laboratory, whereas home dreams can often be selected for discussion on the basis of what appears to be a more interesting or intriguing or useful dream. Also, the dreams were shorter than would be expected from spontaneous recall, due to their mostly occurring in the middle of the night, and participants mostly were not experiencing major life concerns or events, which might have more clearly affected dream content and possibly afforded greater opportunity for discussion and insight.

\section{Metaphor}

One possible explanation for the Exploration-Insight results could be that the presence of metaphor and new associations enables dreams to be a greater source of insight than daydreams. Although waking life events, concerns and experiences can be represented literally in dreams, most of the time they are modified (Fosse et al., 2003; Vallat et al., 2017). According to Domhoff (2015), these modified, sometimes unusual or bizarre, elements in dream reports can aid the figurative embodiment of the dreamer's concerns and conceptualizations. As with metaphors in general, dream metaphors may restructure waking life cognition, even if the waking life issues are familiar and already well- considered and explored. According to Ullman (1969), when social relations are not understood and hence cannot be conceptualized, they can achieve expression in the dream "in a personal idiom and by as apt a metaphor as the individual can construct to describe what it feels like" (p. 700) and that metaphor is "the natural vehicle for allowing the new to gain expression" (p. 703).

The presence of metaphors, nonliteral references to waking life experiences, may enable the dream to provide personal insight, such as about relationships with others, emotional issues, self-knowledge, and even therapeutic insight in a manner similar to the effects of metaphors in psychotherapy (Orange, 2011). For example, Angus and Rennie (1989) described the collaborative exploration of spontaneously generated metaphors in psychotherapy and state that the metaphor can symbolize inner experience in a shorthand manner through an associative link to the experience, and by representing aspects of self-identity or by symbolizing role relationship patterns. For example, in the illustrative dream and realization described in the results section, there was in waking life a marble table for meals at the last family holiday before the participant moved to university, and in the dream a marble staircase was the link between life at the family home and life at the new university hall of residence.

Landau, Meier, and Keefer's (2010) experimental studies on metaphor show that people construe many aspects of the social world, including social thought and attitudes, using conceptual metaphors that apply concrete concepts so as to process information about more abstract concepts. They provide the example that participants holding a warm beverage rate themselves as being emotionally closer to their friends and family compared with participants holding a cold beverage. Such construals often occur in the absence of conscious deliberation, and similarly, during a dream, the metaphor is not a subject of deliberation, and would usually not be considered or deliberated even when awake. Landau et al. (2010) stated that "a metaphorenriched perspective can bridge social cognition with the study of creativity" (p. 1062). Metaphors in dreams may well thus similarly be a source of creativity and insight about the waking life target of the metaphor. 
The physical nature of certain metaphors accords with empirical work on embodied cognition and embodied metaphor, where embodiment activates cognitive processes that facilitate the generation of new ideas and connections. For example, participants scored higher on a creativity test when they were seated outside a box compared with participants who sat inside it (Leung et al., 2012), thus embodying literally the metaphor of "thinking outside the box." Leung et al. (2012) concluded from several such studies that "embodiment can potentially enlarge - not just activate-repertoires of knowledge by triggering cognitive processes that are conducive to generating creative solutions" ( $\mathrm{p}$. 508). The endogenous embodied metaphors in dreams might (a) exert a similar effect on attributions and cognition and (b) be a counterpart to the experimental paradigm of targeted memory reactivation, in which a stimulus present during learning when awake (e.g., an odor or sound) is presented again when the participant is asleep and can enhance memory consolidation (Rudoy, Voss, Westerberg, \& Paller, 2009). Accordingly, dreams might be an expression of or even engender memory reactivation during sleep. For some dreams schema reactivation (Lewis \& Durrant, 2011) might take the form of metaphors rather than of schemas or of simple environmental stimuli. The basis for this complex reactivation would be the hallucinatory environment of the dream.

According to Windt (2015, p. 561), there is spatiotemporal self-location of the dreamer in the dream, relative to other persons and objects in the dream, such that the dreamer possesses beliefs and emotions about the ongoing dream. Indeed, the hallucinatory nature of dreams may be needed so as to fully experience these emotions and to enable some aspects of the sleepdependent processing of these emotions. Along these lines, according to Domhoff (2017), dreaming is the embodiment and enactment of both waking life conceptualizations and personal concerns. The difference in hallucinatory quality of dreams and daydreams may explain the Exploration-Insight differences between dreams and daydreams, possibly mediated by the presence of embodied metaphor. Important to this argument, given the complexity of depicting metaphors, are findings that dreams have longer scenes and thematic sequences than do daydreams (Reinsel, Wollman, \& Antrobus,
1986), with plot development characterized by reports having less unit-to-unit variation as the dream gets longer, and with characters and settings being maintained rather than discontinuous (Foulkes \& Schmidt, 1983).

\section{Confounds}

There are, however, possible confounds in interpreting our findings, in that dreams and daydreams did not just differ on the presence of hallucinatory imagery. Daydream reports were shorter than dream reports and the time spent discussing the daydreams was approximately five minutes shorter than the time spent discussing dreams. However, there were no significant differences between dream and daydream discussions in participant ratings of "I was able to explore my (day)dream thoroughly during the session," "I felt like I was very involved in working with this (day)dream during the session," and in ratings for reliving the dream or daydream and in reexperiencing the feelings of the dream or daydream. These findings demonstrate that participants perceived the dream and daydream discussions similarly in terms of engagement and thoroughness and this raises the possibility that extending the discussion time for daydreams so as to match more closely the time for dream discussion might engender discomfort and be perceived as artificial. Moreover, extended discussion time would not have been possible in cases in which the daydream was examined first, as the length of time needed for discussing the dream would not have been known at that point.

A further reason for not concluding that differences in the report lengths or discussion durations are the reason for Exploration-Insight outcome differences between conditions is that within each condition, length of report and length of discussion were not predictive of Exploration-Insight score. Furthermore, in Edwards et al. (2013), there was also no significant association between length of dream report and Exploration-Insight. In the current study dreams and daydream reports differed significantly on Dreamlike Fantasy, and, with this variable as a covariate, the initial significant difference in Exploration-Insight between dreams and daydreams became nonsignificant. Accordingly, this feature of dreams, which refers to level of hallucination, might contribute 
to the differences in Exploration-Insight between conditions.

\section{Electrophysiological Correlates of Exploration-Insight}

Right frontal theta power in the three minutes prior to waking from N2 sleep was significantly associated with Exploration-Insight scores obtained after N2 dream discussion. This result accords with recent studies highlighting the role of NREM sleep and its related theta activity in the processing of emotional memories (e.g., Cairney et al., 2015; Lehmann et al., 2016). However, and contrary to our hypothesis, this relationship did not hold between REM sleep theta power and Exploration-Insight after REM dream discussion. It is not clear why this outcome was evident in N2 but not in the REM dream condition. However, we can speculate that the unique functional brain organization in REM sleep, including differences in memory consolidation from NREM sleep (Rauchs et al., 2004; Rauchs, Desgranges, Foret, \& Eustache, 2005), favors the hyperassociativity of memories that forms the basis for novel dream imagery and metaphors (Malinowski \& Horton, 2015), while such processing is achieved in N2 only when higher levels of theta activity are present.

\section{Limitations}

A limitation of our study is that, although clear metaphoric images were reported and were indicated by responses to the realization and G(D)DI questions, and although much previous literature has detailed empirical and theoretical reasons to emphasize the metaphorical nature of much dream imagery, we did not formally assess metaphors in dreams. This was because it was not feasible to add extra data collection to the demanding rating protocol, and also it was questionable whether independent judges would be suitable for such a task and able to reliably rate highly idiosyncratic metaphors. Future work should extend quantitative assessment in this regard, with ratings of, for example, conventionality and aptness of metaphors (Thibodeau \& Durgin, 2011), surprisingness, comprehensibility, conventionality, and metaphoricity of content (Thibodeau, Sikos, \& Durgin, 2016), in relation to levels of insight.
The possibility of an experimenter effect needs to be addressed in that two experimenters were part of the dream group and its discussions and were aware of the hypotheses of the study. In the dream group the experimenters briefly discussed the dreams and daydreams of the participant in terms of their own lives. However, this part of the procedure was aimed to demonstrate to participants that it is possible to relate the dream to their own waking life, and there was negligible difference in times for the experimenters discussing the dream of the participant as if it were their own compared to such discussion time for daydreams. The dream group experimenters also made suggestions to participants regarding links between dream content and participants' waking lives, in the orchestration phase; however, this procedure is predicated on the benefit and sometimes necessity of having the assistance of others in deciphering relationships between dreams (and here daydreams) and waking life. The experimenters were not told which reports were dreams and which were daydreams and we also note the lack of difference between dream and daydream conditions on G(D)DI items referring to thoroughness of exploring and involvement in working with the dream or daydream, and the lack of difference in reliving the dream or daydream. Furthermore, the dream and daydream discussions had similar levels of occurrence of reported realizations. We contend that these findings provide evidence for equal treatment effects across the dream and daydream conditions and constitute evidence against an experimenter effect (i.e., explicit or implicit effects of the experimenters that favor confirming research hypotheses).

Consideration is also needed regarding the potential role of demand characteristics (Sharpe \& Whelton, 2016) in participants answering the realization question and G(D)DI, in that some participants might have explicitly or implicitly believed or been affected by the common cultural belief that dreams are a source of hidden truths (Morewedge \& Norton, 2009). Nevertheless, dream and daydream conditions did not differ significantly on reporting a realization, nor on the G(D)DI Action subscale, which includes items on taking action about one's cognitions or behavior as a result of examining the dream, such action also being part of the cultural beliefs about dreams identified by Morewedge and 
Norton (2009). Furthermore, for the REM and daydreaming conditions, we found a significant association between Exploration-Insight score and the ratings by independent judges of the realization descriptions written by participants after the discussions. This external correlate supports the validity of the participants' Exploration-Insight scores and suggests that the Exploration-Insight differences between conditions are not a function of cultural beliefs about dreams. Regarding this difference between conditions, it is of note for the daydreaming condition that there is also a widespread cultural belief that periods of quiet wakefulness can elicit incubation of creativity and insight (Weisberg, 1986). Whereas Morewedge and Norton (2009) provide evidence for cultural beliefs about hidden truths in dreams and about taking action as a result of dream content, they do acknowledge that the cultural view that dreams provide some hidden insight into waking life may be accurate, albeit that expert assistance may be needed to identify insights. They conclude that "if sleep lends insight into solving abstract problems ...., perhaps sleep and dreaming provide insight into the concrete problem of making sense of ourselves as well" (p. 261). It may be that the current results indeed provide evidence for the validity of this cultural belief about dreams.

It is possible, however, that our findings underestimate the gains that might result from considering dreams, as it may be that full benefits from dream discussions do not occur on the brief timescales of discussion and assessment used in the current study. Moreover, if dreams were discussed on the morning after being in the sleep laboratory, rather than some days afterward, participants may have benefited more from the discussion, due to being able to retrieve more details of their dreams and being better able to identify mnemonic sources of the dream content. Furthermore, our results might underestimate gains that could occur with (a) a larger group (a group of eight is more usual), (b) researchers with clinical experience, (c) researchers already known to participants, or (d) participants with greater experience in examining their dreams. Additionally, as Heaton, Hill, Hess, Leotta, and Hoffman (1998) suggested, particular types of dreams, such as troubling or recurrent ones, are arguably more important to explore, whereas the current study used dreams from the sleep laboratory irrespective of content or type, and without selection by participants. Of note is that Kuiken and Smith (1991) found that metaphors created after considering impactful dreams are more easily generated and more apt than are metaphors created after considering ordinary dreams.

The fact that we selected participants who were frequent dream recallers, sleeping at least $7 \mathrm{hr}$ per night, may limit the generalizability of our findings. For example, high and low dream recallers differ on a number of personality and sleep measures and in neurophysiological activity during sleep and wakefulness (Eichenlaub, Bertrand, et al., 2014; Eichenlaub, Nicolas, et al., 2014).

\section{Clinical Implications}

The Ullman method, when used in a lay group setting, does not have clinical or direct therapeutic intent, in that the aim is to assist the dreamer to connect dream content with recent waking life experience. The method specifies an interplay for the dreamer between safety and curiosity, with the dreamer deciding the degree to which self-revelation occurs. The method thus allows for the formation of supportive and empathic relationships while exploring life issues with oneself and others (Krippner, Gabel, Green, \& Rubien, 1994) and can therefore have potential for outcomes pertinent to therapeutic or personal growth. When used in a clinical setting the primary potential is that, through the strict application of the stages of the method, it is effective for rigorous data collection, related to the dream report and the waking life context and possible stimuli for the dream, which may promote insight and behavioral change (Ullman \& Limmer, 1999). According to Ullman (1996), the dream is a response to waking life tensions and emotions, a view supported by the empirical literature (Schredl, 2006; Malinowski \& Horton, 2014; Vallat et al., 2017). Discussing the dream content and examining the dream carefully, often from multiple perspectives, may point to or elicit precipitating sources of emotion in waking life. In some instances, such exploration may be clinically relevant, and important personal issues may become amenable to further in-depth exploration, abetted by the psychological distance that exists between the client and the material evoked by a dream, and 
the felt safety of that distance (Pesant \& Zadra, 2004).

\section{Conclusions}

Fox et al. (2013) call for investigations of the "putative functionality for spontaneous thought and dreaming" (p. 13). They stated,

\footnotetext{
though at least some spontaneous thoughts seem of undeniable value to individuals, there appear too to be many less-than-useful thoughts, and incoherent dreams. Future work can address this issue by exploring differential neural correlates and subjective qualities of dreams and spontaneous thoughts related to any number of factors of interest, such as creativity and planning for the future. (p. 13)
}

We indeed do this here, ascertaining the usefulness of what are often characterized as "lessthan-useful thoughts, and incoherent dreams." We found that participants view the dreams collected as a source of insight. Studies are now needed to address both (a) the quantitative assessment of the frequency and characteristics of embodied metaphors that engender instances of insight and (b) the relationship of electrophysiological variables during sleep to the degree to which dreams elicit insight.

\section{References}

Angus, L. E., \& Rennie, D. L. (1989). Envisioning the representational world: The client's experience of metaphoric expression in psychotherapy. Psychotherapy: Theory, Research, \& Practice, 26, 372-379. http://dx.doi.org/10.1037/h0085448

Antrobus, J. S. (1977). The dream as metaphor: An information-processing and learning model. Journal of Mental Imagery, 2, 327-338.

Antrobus, J. (1983). REM and NREM sleep reports: Comparison of word frequencies by cognitive classes. Psychophysiology, 20, 562-568. http://dx .doi.org/10.1111/j.1469-8986.1983.tb03015.x

Barrett, D. (2017). Dreams and creative problemsolving. Annals of the New York Academy of Sciences, 1406, 64-67. http://dx.doi.org/10.1111/ nyas. 13412

Baylor, G. W., \& Cavallero, C. (2001). Memory sources associated with REM and NREM dream reports throughout the night: A new look at the data. Sleep, 24, 165-170.

Buckner, R. L., Andrews-Hanna, J. R., \& Schacter, D. L. (2008). The brain's default network: Anatomy, function, and relevance to disease. Annals of the New York Academy of Sciences, 1124, 1-38. http://dx.doi.org/10.1196/annals.1440.011
Cai, D. J., Mednick, S. A., Harrison, E. M., Kanady, J. C., \& Mednick, S. C. (2009). REM, not incubation, improves creativity by priming associative networks. Proceedings of the National Academy of Sciences of the United States of America, 106, 10130-10134. http://dx.doi.org/10.1073/pnas .0900271106

Cairney, S. A., Durrant, S. J., Power, R., \& Lewis, P. A. (2015). Complementary roles of slow-wave sleep and rapid eye movement sleep in emotional memory consolidation. Cerebral Cortex, 25, 1565-1575. http://dx.doi.org/10.1093/cercor/ bht 349

Carr, M., \& Nielsen, T. (2015a). Daydreams and nap dreams: Content comparisons. Consciousness and Cognition, 36, 196-205. http://dx.doi.org/10.1016/ j.concog.2015.06.012

Carr, M., \& Nielsen, T. (2015b). Morning rapid eye movement sleep naps facilitate broad access to emotional semantic networks. Sleep, 38, 433-443. http://dx.doi.org/10.5665/sleep.4504

Cartwright, R. D., Tipton, L. W., \& Wicklund, J. (1980). Focusing on dreams. A preparation program for psychotherapy. Archives of General Psychiatry, 37, 275-277. http://dx.doi.org/10.1001/ archpsyc.1980.01780160045004

Cohen, J. (1988). Statistical power analysis for the behavioural sciences (2nd ed.). Mahwah, NJ: Lawrence Erlbaum.

Cowdin, N., Kobayashi, I., \& Mellman, T. A. (2014). Theta frequency activity during rapid eye movement (REM) sleep is greater in people with resilience versus PTSD. Experimental Brain Research, 232, 1479-1485. http://dx.doi.org/10.1007/ s00221-014-3857-5

Darsaud, A., Wagner, U., Balteau, E., Desseilles, M., Sterpenich, V., Vandewalle, G., . . . Maquet, P. (2011). Neural precursors of delayed insight. Journal of Cognitive Neuroscience, 23, 1900-1910. http://dx.doi.org/10.1162/jocn.2010.21550

Davidson, J., \& Lynch, S. (2012). Thematic, literal and associative dream imagery following a highimpact event. Dreaming, 22, 58-69. http://dx.doi .org/10.1037/a0026273

Diekelmann, S., \& Born, J. (2010). The memory function of sleep. Nature Reviews Neuroscience, 11, 114-126. http://dx.doi.org/10.1038/nrn2762

Domhoff, G. W. (2003). The scientific study of dreams: Neural networks, cognitive development, and content analysis. Washington, DC: American Psychological Associatioon Press. http://dx.doi .org/10.1037/10463-000

Domhoff, G. W. (2005). Refocusing the neurocognitive approach to dreams: A critique of the Hobson versus Solms debate. Dreaming, 15, 3-20. http:// dx.doi.org/10.1037/1053-0797.15.1.3

Domhoff, G. W. (2011). The neural substrate for dreaming: Is it a subsystem of the default network? 
Consciousness and Cognition, 20, 1163-1174. http://dx.doi.org/10.1016/j.concog.2011.03.001

Domhoff, G. W. (2015). Dreaming as embodied simulation: A widower's dreams of his deceased wife. Dreaming, 25, 232-256. http://dx.doi.org/10.1037/ a0039291

Domhoff, G. W. (2017). The invasion of the concept snatchers: The origins, distortions, and future of the continuity hypothesis. Dreaming, 27, 14-39. http://dx.doi.org/10.1037/drm0000047

Domhoff, G. W. (2018). The emergence of dreaming: Mind-wandering, embodied simulation, and the default network. New York, NY: Oxford University Press. http://dx.doi.org/10.1093/oso/978019 0673420.001 .0001

Durrant, S. J., Cairney, S. A., McDermott, C., \& Lewis, P. A. (2015). Schema-conformant memories are preferentially consolidated during REM sleep. Neurobiology of Learning and Memory, 122, 41-50. http://dx.doi.org/10.1016/j.nlm.2015 .02 .011

Edwards, C. L., Malinowski, J. E., McGee, S. L., Bennett, P. D., Ruby, P. M., \& Blagrove, M. T. (2015). Comparing personal insight gains due to consideration of a recent dream and consideration of a recent event using the Ullman and Schredl dream group methods. Frontiers in Psychology, 6, 831. http://dx.doi.org/10.3389/fpsyg.2015.00831

Edwards, C. L., Ruby, P. M., Malinowski, J. E., Bennett, P. D., \& Blagrove, M. T. (2013). Dreaming and insight. Frontiers in Psychology, 4, 979. http://dx.doi.org/10.3389/fpsyg.2013.00979

Eichenlaub, J.-B., Bertrand, O., Morlet, D., \& Ruby, P. (2014). Brain reactivity differentiates subjects with high and low dream recall frequencies during both sleep and wakefulness. Cerebral Cortex, 24, 1206-1215. http://dx.doi.org/10.1093/cercor/ bhs 388

Eichenlaub, J.-B., Nicolas, A., Daltrozzo, J., Redouté, J., Costes, N., \& Ruby, P. (2014). Resting brain activity varies with dream recall frequency between subjects. Neuropsychopharmacology, 39, 1594-1602. http://dx.doi.org/10.1038/npp.2014.6

Eichenlaub, J.-B., van Rijn, E., Gaskell, M. G., Lewis, P. A., Maby, E., Malinowski, J. E., . . . Blagrove, M. (2018). Incorporation of recent waking-life experiences in dreams correlates with frontal theta activity in REM sleep. Social Cognitive and Affective Neuroscience, 13, 637-647. http:// dx.doi.org/10.1093/scan/nsy041

Erdelyi, M. H. (2006). The unified theory of repression. Behavioral and Brain Sciences, 29, 499-511. http://dx.doi.org/10.1017/S0140525X06009113

Fosse, M. J., Fosse, R., Hobson, J. A., \& Stickgold, R. J. (2003). Dreaming and episodic memory: A functional dissociation? Journal of Cognitive Neuroscience, 15, 1-9. http://dx.doi.org/10.1162/ 089892903321107774
Fosse, R., Stickgold, R., \& Hobson, J. A. (2001). Brain-mind states: Reciprocal variation in thoughts and hallucinations. Psychological Science, 12, 3036. http://dx.doi.org/10.1111/1467-9280.00306

Foulkes, D. (1985). Dreaming: A cognitivepsychological analysis. New York, NY: Routledge.

Foulkes, D., \& Schmidt, M. (1983). Temporal sequence and unit composition in dream reports from different stages of sleep. Sleep, 6, 265-280. http:// dx.doi.org/10.1093/sleep/6.3.265

Foulkes, D., Spear, P. S., \& Symonds, J. D. (1966). Individual differences in mental activity at sleep onset. Journal of Abnormal Psychology, 71, 280286. http://dx.doi.org/10.1037/h0023581

Fox, K. C., Nijeboer, S., Solomonova, E., Domhoff, G. W., \& Christoff, K. (2013). Dreaming as mind wandering: Evidence from functional neuroimaging and first-person content reports. Frontiers in Human Neuroscience, 7, 412. http://dx.doi.org/10 .3389/fnhum.2013.00412

Freud, S. (1953). The interpretation of dreams. In J. Strachey (Ed. \& Trans.), The standard edition of the complete psychological works of Sigmund Freud (Vols. 4, 5). London, United Kingdom: Hogarth Press. (Original work published 1900)

Groch, S., Wilhelm, I., Diekelmann, S., \& Born, J. (2013). The role of REM sleep in the processing of emotional memories: Evidence from behavior and event-related potentials. Neurobiology of Learning and Memory, 99, 1-9. http://dx.doi.org/10.1016/j .nlm.2012.10.006

Hartmann, E. (1995). Making connections in a safe place: Is dreaming psychotherapy? Dreaming, 5, 213-228. http://dx.doi.org/10.1037/h0094437

Hartmann, E. (1996). Outline for a theory on the nature and functions of dreaming. Dreaming, 6, 147-170. http://dx.doi.org/10.1037/h0094452

Hartmann, E. (2011). The nature and functions of dreaming. New York, NY: Oxford University Press.

Heaton, K. J., Hill, C. E., Hess, S. A., Leotta, C., \& Hoffman, M. A. (1998). Assimilation in therapy involving interpretation of recurrent and nonrecurrent dreams. Psychotherapy: Theory, Research, \& Practice, 35, 147-162. http://dx.doi.org/10.1037/ h0087784

Heaton, K. J., Hill, C. E., Petersen, D. A., Rochlen, A. B., \& Zack, J. S. (1998). A comparison of therapist-facilitated and self-guided dream interpretation sessions. Journal of Counseling Psychology, 45, 115-122. http://dx.doi.org/10.1037/00220167.45 .1 .115

Hill, C. E. (1996). Working with dreams in psychotherapy. New York, NY: Guilford Press.

Hill, C. E., Diemer, R., Hess, S., Hilliger, A., \& Seeman, R. (1993). Are the effects of dream interpretation on session quality due to the dream itself, 
to projection or the interpretation process? Dreaming, 3, 269-280. http://dx.doi.org/10.1037/ h0094385

Hobson, J. A., \& Schredl, M. (2011). The continuity and discontinuity between waking and dreaming: A dialogue between Michael Schredl and Allan Hobson concerning the adequacy and completeness of these notions. International Journal of Dream Research, 4, 3-7.

Hutchison, I. C., \& Rathore, S. (2015). The role of REM sleep theta activity in emotional memory. Frontiers in Psychology, 6, 1439. http://dx.doi.org/ 10.3389/fpsyg.2015.01439

Iber, C., Ancoli-Israel, S., Chesson, A., \& Quan, S. F., \& the American Academy of Sleep and Medicine. (2007). The AASM manual for the scoring of sleep and associated events: Rules, terminology and technical specifications (1st ed.). Winchester, IL: American Academy of Sleep Medicine.

Ioannides, A. A., Kostopoulos, G. K., Liu, L., \& Fenwick, P. B. C. (2009). MEG identifies dorsal medial brain activations during sleep. NeuroImage, 44, 455-468. http://dx.doi.org/10.1016/j .neuroimage.2008.09.030

Knox, S., Hill, C. E., Hess, S. A., \& Crook-Lyon, R. E. (2008). Case studies of the attainment of insight in dream sessions: Replication and extension. Psychotherapy Research, 18, 200-215. http:// dx.doi.org/10.1080/10503300701432242

Kounios, J., \& Beeman, M. (2009). The Aha! moment: The cognitive neuroscience of insight. Current Directions in Psychological Science, 18, 210216. http://dx.doi.org/10.1111/j.1467-8721.2009 .01638.x

Krippner, S., Gabel, S., Green, J., \& Rubien, R. (1994). Community applications of an experiential group approach to teaching dreamwork. Dreaming, 4, 215-222. http://dx.doi.org/10.1037/ h0094414

Kuiken, D., \& Smith, L. (1991). Impactful dreams and metaphor generation. Dreaming, 1, 135-145. http://dx.doi.org/10.1037/h0094326

Lakens, D. (2013). Calculating and reporting effect sizes to facilitate cumulative science: A practical primer for $t$-tests and ANOVAs. Frontiers in Psychology, 4, 863. http://dx.doi.org/10.3389/fpsyg .2013 .00863

Lakoff, G. (1993). How metaphor structures dreams: The theory of the conceptual metaphor. Dreaming, 3, 77-98. http://dx.doi.org/10.1037/h0094373

Lakoff, G. (2014). Mapping the brain's metaphor circuitry: Metaphorical thought in everyday reason. Frontiers in Human Neuroscience, 8, 958. http://dx.doi.org/10.3389/fnhum.2014.00958

Lakoff, G., \& Johnson, M. (1980). Metaphors we live by. IL: University of Chicago Press.
Landau, M. J., Meier, B. P., \& Keefer, L. A. (2010). A metaphor-enriched social cognition. Psychological Bulletin, 136, 1045-1067. http://dx.doi.org/10 $.1037 / \mathrm{a} 0020970$

Landmann, N., Kuhn, M., Maier, J.-G., Spiegelhalder, K., Baglioni, C., Frase, L., . . . Nissen, C. (2015). REM sleep and memory reorganization: Potential relevance for psychiatry and psychotherapy. Neurobiology of Learning and Memory, 122, 28-40. http://dx.doi.org/10.1016/j.nlm.2015.01 .004

Lara-Carrasco, J., Simard, V., Saint-Onge, K., Lamoureux-Tremblay, V., \& Nielsen, T. (2013). Maternal representations in the dreams of pregnant women: A prospective comparative study. Frontiers in Psychology, 4, 551. http://dx.doi.org/10 .3389/fpsyg.2013.00551

Legrand, D., \& Ruby, P. (2009). What is selfspecific? Theoretical investigation and critical review of neuroimaging results. Psychological Review, 116, 252-282. http://dx.doi.org/10.1037/ a0014172

Lehmann, M., Schreiner, T., Seifritz, E., \& Rasch, B. (2016). Emotional arousal modulates oscillatory correlates of targeted memory reactivation during NREM, but not REM sleep. Scientific Reports, 6, 39229. http://dx.doi.org/10.1038/srep39229

Leung, A. K.-y., Kim, S., Polman, E., Ong, L. S., Qiu, L., Goncalo, J. A., \& Sanchez-Burks, J. (2012). Embodied metaphors and creative "acts." Psychological Science, 23, 502-509. http://dx.doi .org/10.1177/0956797611429801

Levin, R., \& Nielsen, T. A. (2007). Disturbed dreaming, posttraumatic stress disorder, and affect distress: A review and neurocognitive model. Psychological Bulletin, 133, 482-528. http://dx.doi.org/ 10.1037/0033-2909.133.3.482

Lewis, P. A., \& Durrant, S. J. (2011). Overlapping memory replay during sleep builds cognitive schemata. Trends in Cognitive Sciences, 15, 343-351. http://dx.doi.org/10.1016/j.tics.2011.06.004

Llewellyn, S. (2013). Such stuff as dreams are made on? Elaborative encoding, the ancient art of memory, and the hippocampus. Behavioral and Brain Sciences, 36, 589-607. http://dx.doi.org/10.1017/ S0140525X12003135

Malinowski, J., \& Horton, C. L. (2014). Evidence for the preferential incorporation of emotional waking-life experiences into dreams. Dreaming, 24, 18-31. http://dx.doi.org/10.1037/a0036017

Malinowski, J. E., \& Horton, C. L. (2015). Metaphor and hyperassociativity: The imagination mechanisms behind emotion assimilation in sleep and dreaming. Frontiers in Psychology, 6, 1132. http:// dx.doi.org/10.3389/fpsyg.2015.01132

Maquet, P., Péters, J., Aerts, J., Delfiore, G., Degueldre, C., Luxen, A., \& Franck, G. (1996). Functional neuroanatomy of human rapid-eye-move- 
ment sleep and dreaming. Nature, 383, 163-166. http://dx.doi.org/10.1038/383163a0

Maquet, P., \& Ruby, P. (2004). Psychology: Insight and the sleep committee. Nature, 427, 304-305. http://dx.doi.org/10.1038/427304a

Maquet, P., Ruby, P., Maudoux, A., Albouy, G., Sterpenich, V., Dang-Vu, T., . . . Laureys, S. (2005). Human Cognition in REM sleep and the activity profile within frontal and parietal cortices: A reappraisal of neuroimaging data. Progress in Brain Research, 150, 219-227. http://dx.doi.org/ 10.1016/S0079-6123(05)50016-5

Mittner, M., Hawkins, G. E., Boekel, W., \& Forstmann, B. U. (2016). A neural model of mind wandering. Trends in Cognitive Sciences, 20, 570578. http://dx.doi.org/10.1016/j.tics.2016.06.004

Morewedge, C. K., \& Norton, M. I. (2009). When dreaming is believing: The (motivated) interpretation of dreams. Journal of Personality and Social Psychology, 96, 249-264. http://dx.doi.org/10 $.1037 / \mathrm{a} 0013264$

Nielsen, T. A. (2000). A review of mentation in REM and NREM sleep: "Covert" REM sleep as a possible reconciliation of two opposing models. Behavioral and Brain Sciences, 23, 851-866. http:// dx.doi.org/10.1017/S0140525X0000399X

Nishida, M., Pearsall, J., Buckner, R. L., \& Walker, M. P. (2009). REM sleep, prefrontal theta, and the consolidation of human emotional memory. Cerebral Cortex, 19, 1158-1166. http://dx.doi.org/10 $.1093 /$ cercor/bhn 155

Nofzinger, E. A., Mintun, M. A., Wiseman, M., Kupfer, D. J., \& Moore, R. Y. (1997). Forebrain activation in REM sleep: An FDG PET study. Brain Research, 770, 192-201. http://dx.doi.org/10 .1016/S0006-8993(97)00807-X

Noreika, V., Valli, K., Markkula, J., Seppälä, K., \& Revonsuo, A. (2010). Dream bizarreness and waking thought in schizophrenia. Psychiatry Research, 178, 562-564. http://dx.doi.org/10.1016/j.psychres .2010 .04 .034

Orange, D. M. (2011). Speaking the unspeakable: "The Implicit," traumatic living memory, and the dialogue of metaphors. International Journal of Psychoanalytic Self Psychology, 6, 187-206. http://dx.doi.org/10.1080/15551024.2011.552171

Perogamvros, L., Dang-Vu, T. T., Desseilles, M., \& Schwartz, S. (2013). Sleep and dreaming are for important matters. Frontiers in Psychology, 4, 474. http://dx.doi.org/10.3389/fpsyg.2013.00474

Pesant, N., \& Zadra, A. (2004). Working with dreams in therapy: What do we know and what should we do? Clinical Psychology Review, 24, 489-512. http://dx.doi.org/10.1016/j.cpr.2004.05.002

Popa, D., Duvarci, S., Popescu, A. T., Léna, C., \& Paré, D. (2010). Coherent amygdalocortical theta promotes fear memory consolidation during paradoxical sleep. Proceedings of the National Acad- emy of Sciences of the United States of America, 107, 6516-6519. http://dx.doi.org/10.1073/pnas .0913016107

Prehn-Kristensen, A., Munz, M., Molzow, I., Wilhelm, I., Wiesner, C. D., \& Baving, L. (2013). Sleep promotes consolidation of emotional memory in healthy children but not in children with attention-deficit hyperactivity disorder. PLoS ONE, 8, e65098. http://dx.doi.org/10.1371/journal .pone.0065098

Propper, R. E., Stickgold, R., Keeley, R., \& Christman, S. D. (2007). Is television traumatic? Dreams, stress, and media exposure in the aftermath of September 11, 2001. Psychological Science, 18, 334-340. http://dx.doi.org/10.1111/j .1467-9280.2007.01900.x

Rauchs, G., Bertran, F., Guillery-Girard, B., Desgranges, B., Kerrouche, N., Denise, P., . . . Eustache, F. (2004). Consolidation of strictly episodic memories mainly requires rapid eye movement sleep. Sleep, 27, 395-401. http://dx.doi .org/10.1093/sleep/27.3.395

Rauchs, G., Desgranges, B., Foret, J., \& Eustache, F. (2005). The relationships between memory systems and sleep stages. Journal of Sleep Research, 14, 123-140. http://dx.doi.org/10.1111/j.13652869.2005.00450.x

Reinsel, R., Wollman, M., \& Antrobus, J. S. (1986). Effects of environmental context and cortical activation on thought. Journal of Mind and Behavior, 7, 259-276.

Revonsuo, A., Tuominen, J., \& Valli, K. (2015). The avatars in the machine: Dreaming as a simulation of social reality. In T. Metzinger \& J. M. Windt (Eds), Open MIND (32[T], pp. 1-28). Frankfurt am Main, Germany: MIND Group. http://dx.doi .org/10.15502/9783958570375

Ruby, P. M. (2011). Experimental research on dreaming: State of the art and neuropsychoanalytic perspectives. Frontiers in Psychology, 2, 286. http://dx.doi.org/10.3389/fpsyg.2011.00286

Rudoy, J. D., Voss, J. L., Westerberg, C. E., \& Paller, K. A. (2009). Strengthening individual memories by reactivating them during sleep. Science, 326, 1079. http://dx.doi.org/10.1126/science.1179013

Schredl, M. (2006). Factors affecting the continuity between waking and dreaming: Emotional intensity and emotional tone of the waking-life event. Sleep and Hypnosis, 8, 1-5.

Schredl, M., \& Piel, E. (2008). Interest in dream interpretation: A gender difference. Dreaming, 18, 11-15. http://dx.doi.org/10.1037/1053-0797.18 .1 .11

Sharpe, D., \& Whelton, W. J. (2016). Frightened by an old scarecrow: The remarkable resilience of demand characteristics. Review of General Psychology, 20, 349-368. http://dx.doi.org/10.1037/ gpr0000087 
Solms, M. (1997). The neuropsychology of dreams: A clinico-anatomical study. Mahwah, NJ: Erlbaum.

Solms, M. (2000). Dreaming and REM sleep are controlled by different brain mechanisms. Behavioral and Brain Sciences, 23, 843-850. http://dx .doi.org/10.1017/S0140525X00003988

Speth, C., \& Speth, J. (2016). The borderlands of waking: Quantifying the transition from reflective thought to hallucination in sleep onset. Consciousness and Cognition, 41, 57-63. http://dx.doi.org/ 10.1016/j.concog.2016.01.009

States, B. O. (1998). Dreaming as psychosis: Rereading Allan Hobson. Dreaming, 8, 137-148. http://dx.doi.org/10.1037/h0094485

Stickgold, R., \& Walker, M. P. (2013). Sleepdependent memory triage: Evolving generalization through selective processing. Nature Neuroscience, 16, 139-145. http://dx.doi.org/10.1038/nn .3303

Thibodeau, P. H., \& Durgin, F. H. (2011). Metaphor aptness and conventionality: A processing fluency account. Metaphor and Symbol, 26, 206-226. http://dx.doi.org/10.1080/10926488.2011.583196

Thibodeau, P. H., Sikos, L., \& Durgin, F. H. (2016). What do we learn from rating metaphors? In A. Papafragou, Daniel J. Grodner, D. Mirman, \& J. Trueswell (Eds.), Proceedings of the 38th Annual Conference of the Cognitive Science Society (pp. 1769-1774). Austin, TX: Cognitive Science Society.

Ullman, M. (1969). Dreaming as metaphor in motion. Archives of General Psychiatry, 21, 696-703. http://dx.doi.org/10.1001/archpsyc.1969.017 40240056007

Ullman, M. (1996). Appreciating dreams: A group approach. Thousand Oaks, CA: Sage.

Ullman, M., \& Limmer, C. (1999). Clinical work with dreams. In M. Ullman \& C. Limmer (Eds.), The variety of dream experience (2nd ed., pp. 235-254). Albany, NY: SUNY Press.

Vallat, R., Chatard, B., Blagrove, M., \& Ruby, P. (2017). Characteristics of the memory sources of dreams: A new version of the content-matching paradigm to take mundane and remote memories into account. PLoS ONE, 12, e0185262. http://dx .doi.org/10.1371/journal.pone.0185262

van Rijn, E., Eichenlaub, J.-B., Lewis, P. A., Walker, M. P., Gaskell, M. G., Malinowski, J. E., \& Blagrove, M. (2015). The dream-lag effect: Selective processing of personally significant events during rapid eye movement sleep, but not during slow wave sleep. Neurobiology of Learning and Memory, 122, 98-109. http://dx.doi.org/10.1016/j.nlm .2015.01.009

van Rijn, E., Reid, A. M., Edwards, C. L., Malinowski, J. E., Ruby, P. M., Eichenlaub, J.-B., \& Blagrove, M. T. (2018). Daydreams incorporate recent waking life concerns but do not show delayed ("dream-lag") incorporations. Consciousness and Cognition, 58, 51-59. http://dx.doi.org/ 10.1016/j.concog.2017.10.011

Wagner, U., Gais, S., \& Born, J. (2001). Emotional memory formation is enhanced across sleep intervals with high amounts of rapid eye movement sleep. Learning \& Memory, 8, 112-119. http://dx .doi.org/10.1101/1m.36801

Wagner, U., Gais, S., Haider, H., Verleger, R., \& Born, J. (2004). Sleep inspires insight. Nature, 427, 352-355. http://dx.doi.org/10.1038/nature 02223

Walker, M. P., Liston, C., Hobson, J. A., \& Stickgold, R. (2002). Cognitive flexibility across the sleep-wake cycle: REM-sleep enhancement of anagram problem solving. Cognitive Brain Research, 14, 317-324. http://dx.doi.org/10.1016/ S0926-6410(02)00134-9

Walker, M. P., \& van der Helm, E. (2009). Overnight therapy? The role of sleep in emotional brain processing. Psychological Bulletin, 135, 731-748. http://dx.doi.org/10.1037/a0016570

Wamsley, E. J. (2014). Dreaming and offline memory consolidation. Current Neurology and Neuroscience Reports, 14, 433. http://dx.doi.org/10 .1007/s11910-013-0433-5

Wegner, D. M., Wenzlaff, R. M., \& Kozak, M. (2004). Dream rebound: The return of suppressed thoughts in dreams. Psychological Science, 15, 232-236. http://dx.doi.org/10.1111/j.0963-7214 .2004.00657.x

Weisberg, R. (1986). Creativity: Genius and other myths. New York, NY: W. H. Freeman/Times Books/Henry Holt.

Windt, J. M. (2015). Dreaming: A conceptual framework for philosophy of mind and empirical research. Cambridge, MA: MIT Press. http://dx.doi .org/10.7551/mitpress/9780262028677.001.0001

Received September 22, 2017

Revision received June 27, 2018 Accepted July 23, 2018 